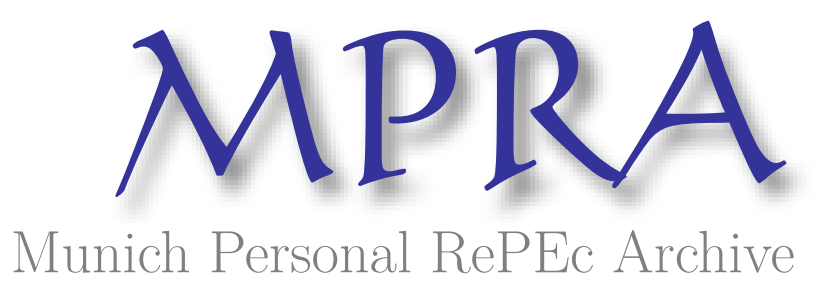

\title{
The Role of CETA on Carbon Dioxide, F-Gasses, Methane, and Nitrous Oxide
}

Qirjo, Dhimitri and Pascalau, Razvan and Krichevskiy, Dmitriy

State University of New York, Plattsburgh, State University of New York, Plattsburgh, Elizabethtown College

14 April 2020

Online at https://mpra.ub.uni-muenchen.de/99646/

MPRA Paper No. 99646, posted 17 Apr 2020 10:52 UTC 


\title{
The Role of CETA on Carbon Dioxide, F-Gasses, Methane, and Nitrous Oxide
}

\author{
Dhimitri Qirjo*, Razvan Pascalau ${ }^{\dagger}$, and Dmitriy Krichevskiy ${ }^{\ddagger}$
}

April 14, 2020

\begin{abstract}
This study empirically investigates how the presence of CETA (Comprehensive Economic and Trade Agreement) may affect per capita emissions of four air pollutants. It follows closely the empirical work of (Qirjo et al., 2019), but it focuses in each category of GHGs. It finds statistically significant evidence suggesting that trade openness between the EU and Canada could help reduce per capita emissions of $\mathrm{CO}_{2}, \mathrm{CH}_{4}$, and $\mathrm{N}_{2} \mathrm{O}$ in a typical CETA member, respectively. In the case of $\mathrm{CO}_{2}$, the presence of CETA may help reduce per capita emissions in almost all CETA members. However, there is empirical evidence that suggests that per capita emissions of $\mathrm{CH}_{4}$ could move from the EU towards Canada due to the implementation of CETA. There is also empirical evidence implying that there could be a shift of emissions per capita of $N_{2} \mathrm{O}$ from Canada towards 8 former EU members due to the implementation of CETA. There is mainly statistically insignificant evidence of a positive relationship between trade intensity of each EU member and Canada and per capita emissions of $H F C s / P F C s / S F_{6}$. Furthermore, the study reports unambiguous empirical evidence in support of Pollution Haven Hypothesis originating from national population density variations ( $\mathrm{PHH} 2$ ) for Canada, in the case of $\mathrm{CH}_{4}$. Moreover, there is also clear evidence consistent to the Pollution Haven Hypothesis due to national income differences (PHH1) for 8 former Communist EU members, in the cases of $N_{2} \mathrm{O}$ and $H F C s / P F C s / S F_{6}$.
\end{abstract}

JEL Classification: F11, F53, Q15

Keywords: Free Trade, Environmental Economics, CETA.

${ }^{*}$ Department of Economics \& Finance, SUNY Plattsburgh, 329 Au Sable Hall, 101 Broad St., Plattsburgh, NY, 12901, USA. E-mail: dqirj001@fiu.edu. Phone: +1-518-564-4200

$\dagger$ Department of Economics \& Finance, SUNY Plattsburgh, 325 Au Sable Hall, 101 Broad St., Plattsburgh, NY, 12901, USA. E-mail: rpasc001@plattsburgh.edu. Phone: +1-518-564-4193.

${ }^{\ddagger}$ Department of Business, Elizabethtown College, 1 Alpha Drive, Elizabethtown, PA, 17022, USA. E-mail: krichevskiyd@etown.edu. Phone: +1-717-361-1271. 


\section{Introduction}

This study follows closely the empirical work of (Qirjo et al., 2019), but it focuses on each of the four main categories of GHGs. Consequently, using a panel dataset of 28 current EU members and Canada over the 1990-2016 time period, the paper investigates the impacts of higher trade intensity between trade partners on per capita emissions of four air pollutants; $\mathrm{CO}_{2}, \mathrm{CH}_{4}, \mathrm{HFCs} / \mathrm{PFCs} / \mathrm{SF}_{6}$, and $\mathrm{N}_{2} \mathrm{O}$, respectively.

The study provides robust and statistically significant evidence suggesting that higher trade intensity between each EU member and Canada could help reduce, on average, per capita emissions of $\mathrm{CO}_{2}, \mathrm{CH}_{4}$, and $\mathrm{N}_{2} \mathrm{O}$, respectively. In particular, holding everything else constant, it yields robust and strongly statistically significant evidence suggesting that one percent increase of a percentage point of the ratio of bilateral trade between each EU member and Canada to GDP, may help reduce annual per capita emissions of $\mathrm{CO}_{2}$, $\mathrm{CH}_{4}$, and $\mathrm{N}_{2} \mathrm{O}$, by about .46 percent, .65 percent, and 1.2 percent, respectively. It also shows that the the presence of CETA (Comprehensive Economic and Trade Agreement) may help reduce per capita emissions of $\mathrm{CO}_{2}$ in almost all CETA members. There is no statistically significant evidence of an increase of $\mathrm{CO}_{2}$ for any CETA member, regardless of the empirical strategy or model employed in the paper. However, there is statistically significant evidence suggesting that per capita emissions of $\mathrm{CH}_{4}$, and $\mathrm{N}_{2} \mathrm{O}$ would increase in 7 CETA members and in 9 EU members, respectively, due to more trade between the EU and Canada. These results stand despite the statistically significant evidence of an negative relationship between the trade intensity variable and each of emissions per capita of these 2 air pollutants. Moreover, the study also indicates that there is a positive but mainly not statistically significant evidence between the trade intensity variable and per capita emissions of $H F C s / P F C s / S F_{6}$. More specifically, holding everything else constant, on average, one percent increase of a percentage point of bilateral trade between Canada and a typical EU member as a portion of GDP may help increase per capita emissions of HFCs/PFCs/SF 6 by about $1.95 \%$.

The above result for $\mathrm{CO}_{2}$ stands because $\mathrm{FEH}$ (Factor Endowment Hypothesis based on the Heckscher-Ohlin theory) and PHH2 (Pollution Haven Hypothesis based on an inverse measurement of population density variations) appear to dominate PHH1 (Pollution Haven Hypothesis based on national per capita income differences). An average EU member is poorer, but very densely populated relative to Canada. In particular, there are $17 \mathrm{EU}$ members that are poorer than Canada, but each EU member is extremely more densely populated than Canada. Thus, following PHH1, a poor EU member may act as a pollution haven because it may adapt lax environmental laws (or simple less effective ways over 
the execution of similar environmental rules and regulations) due to higher trade intensity with Canada. On the other hand, simultaneously, Canada may act as a pollution haven because it is extremely sparsely populated as compared to each CETA member, and therefore, may adapt lax air pollution regulations due to the presence of CETA. Moreover, in Canada, FEH may further increase national air pollution because it is a capital-abundant country relative to a typical EU member. In the sample, there are $15 \mathrm{EU}$ members that are labor-abundant and $13 \mathrm{EU}$ members that are capital-abundant. However, the empirical results imply that for Canada, PHH1 cancels out FEH and PHH2. In other words, the implementation of CETA would have a statistically insignificant impact on per capita emissions of $\mathrm{CO}_{2}$ for Canada, but it may help decrease per capita emissions of $\mathrm{CO}_{2}$ in a typical EU member. Consequently, there is not shift of emissions per capita of $\mathrm{CO}_{2}$ from the EU towards Canada even though per capita emissions of $\mathrm{CO}_{2}$ would generally go down in the EU due to the implementation of CETA.

In the cases of $\mathrm{CH}_{4}$ and $\mathrm{N}_{2} \mathrm{O}$, there is empirical evidence implying that $\mathrm{FEH}$ and $\mathrm{PHH} 2$ dominate $\mathrm{PHH} 1$ for a typical EU member. This domination is also true for Canada, but only in the case of $\mathrm{CH}_{4}$. However, $\mathrm{PHH1}$ dominates $\mathrm{FEH}$ and $\mathrm{PHH} 2$ for Canada in the case of $\mathrm{N}_{2} \mathrm{O}$. The results of the study imply that one would expect a shift of emissions per capita of $\mathrm{CH}_{4}$ from the EU towards Canada due to the implementation of CETA. And, a movement of emissions per capita of $\mathrm{N}_{2} \mathrm{O}$ from Canada towards 8 former Communist EU members as a consequence of the implementation of CETA. The results of the paper suggest that this movement of these two air pollutants from one trade region to the other follows $\mathrm{PHH} 2$ for $\mathrm{CH}_{4}$ and $\mathrm{PHH} 1$ for $\mathrm{N}_{2} \mathrm{O}$. Note that Canada is very sparsely populated as compared to each EU member and a typical EU member is poorer than Canada (where a former Communist $\mathrm{EU}$ member is much poorer than Canada).

There is generally no statistically significant evidence of a relationship between the trade intensity variable and per capita emissions of $H F C s / P F C s / S F_{6}$ under most of the models and empirical strategies used in this paper. This implies that PHH1 cancels out FEH and PHH2 for an average EU member due to more trade with Canada. However, there is limited empirical evidence (only under $M 2$ when employing the fixed effects with cross-sectional robust standard errors technique) implying that $P H H 1$ dominates FEH and PHH2, not only for an average EU member, but also for Canada. In other words, there is a shift of emissions per capita of $H F C s / P F C s / S F_{6}$ from Canada towards a typical EU member due to more trade between these two regions. The result of the paper suggest that the latter result stands mainly because an average EU members is poorer than Canada.

This study provides unambiguous empirical evidence in support of PHH1 and PHH2 as a result of more trade between Canada and the EU. It could be worth noting that this is the 
only study, to the best of our knowledge, that provides clear empirical evidence in support of the pollution haven argument originating from national population density variations (PHH2), following the work of Frankel and Rose (2005). CETA provides an ideal case of analyzing the empirical validity of $\mathrm{PHH} 2$ since Canada is extremely sparsely populated as compared to each EU member. The results of the paper suggest strongly statistically significant evidence consistent to $\mathrm{PHH} 2$ for $\mathrm{CH}_{4}$ due to the implementation of CETA (see the estimates of trade elasticities of $\mathrm{CH}_{4}$ emissions per capita reported in Table 9). This is more apparent for Austria, Belgium, Canada, Cyprus, Czech Republic, Finland, France, Greece, Ireland, Italy, Lithuania, Luxembourg, Portugal, Slovakia, Slovenia, and Sweden. Thus, higher trade between each of these $15 \mathrm{EU}$ members and Canada may help these EU members to stringent their air policy regulations for $\mathrm{CH}_{4}$ following $\mathrm{PHH} 2$. At the same time, more trade between these $15 \mathrm{EU}$ members and Canada may force Canada to adopt lax environmental rules and regulations for $\mathrm{CH}_{4}$, and therefore, act as pollution haven consistent to $\mathrm{PHH}$. Put it differently, the implementation of CETA shifts pollution of $\mathrm{CH}_{4}$ from each of these $15 \mathrm{EU}$ towards Canada following $\mathrm{PHH} 2$.

The results of this study suggest that there is empirical evidence in support of $P H H 1$ for $\mathrm{N}_{2} \mathrm{O}$ and $\mathrm{HFCs} / \mathrm{PFCs} / \mathrm{SF}_{6}$ (see the estimates of trade elasticities of $\mathrm{N}_{2} \mathrm{O}$ and $\mathrm{HFCs} / \mathrm{PFCs} / \mathrm{SF}_{6}$ emissions per capita reported in Tables $10 \& 11$, respectively). This is very apparent, for both pollutants, in some former Communist EU members that are each much poorer than Canada (such as Bulgaria, Croatia, Estonia, Hungary, Latvia, Lithuania, Poland, and Romania), but also in other poor EU members such as Malta for $H F C s / P F C s / S F_{6}$. Consequently, for both these pollutants, each of these 8 former Communist EU members (or Malta for $H F C s / P F C s / S_{6}$ ) will act as pollution haven when trading more with Canada simply because they are poorer than Canada, and therefore, may have/adopt lax environmental rules and regulations (or simply a poor execution of the environmental rules and regulations). Put it differently, the implementation of CETA may help increase per capita emissions of $\mathrm{N}_{2} \mathrm{O}$ and $\mathrm{HFCs} / \mathrm{PFCs} / \mathrm{SF}_{6}$ in these former EU members because pollution would shift from Canada towards these EU members.

The study derives the above results by employing 3 econometric models ( $M 1, M 2$, $\& M 3$ ) and using 4 empirical methodologies for each of these 3 models. In particular, in addition to the usual fixed and random effects methods, the paper employs the fixed effects technique controlling for robust cross-sectional dependence standard errors terms, and the fixed effects specification controlling for robust serial-correlation dependence (DriscollKraay, under MA(2) component) standard errors terms. $M 1$ evaluates the role of trade intensity on pollution in the presence of $P H H 1$ and $F E H$, but in the absence of PHH2. M2 looks at the role of trade intensity on pollution in the presence of $P H H 1, P H H 2$, and FEH. 
$M 3$ tests the effect of trade intensity on pollution in the presence of $P H H 1, P H H 2$, and $F E H$, but also adds 3 dummy variables that are closely related to the trade intensity variable. All three models also include a set of control variables that are commonly used in this literature.

From the policy point of view, it could be important to emphasize the empirical validity of PHH2 and PHH1, when evaluating the environmental impacts of CETA. This is related to the fact that CETA already have two separate chapters that attempt to emphasize the possible environmental impacts of this trade agreement. It is worth noting that there 16 articles of chapter 24 entitled "Trade and Environment", where one of the main goals is to eliminate any possible pollution haven for any CETA member associated to the trade agreement. ${ }^{1}$ The empirical results of this paper do not provide any clues for curing the potential disease of pollution havens due to the implementation of CETA, but they attempt to provide some empirical evidence over the general diagnosis of this disease (pollution haven) that could be created/worsen, due to the implementation of CETA. Looking at the various documents of CETA that are publicly available in the official EU and Canada websites, there are no clear details on what type of mechanism the EU and Canada would take in eliminating these pollution havens (maybe using second best policies such as various trade barriers of goods (productive activities) associated with these pollutants, or first best policies, such enforcing higher environmental standards in the countries that are potential candidates of pollution havens for these pollutants, or the introduction of pollution taxes for these pollutants only in CETA members that are potential candidates of pollution havens).

The main objective of this paper is to follow-up the empirical study of Qirjo et al. (2019) by focusing on the impacts of higher trade intensity between the EU and Canada on each of the main four air pollutants that are part of GHGs, instead on focusing on GHGs in general. In this light, the study highlights the similarities and differences between the former paper and the current one. The main results of this empirical study confirm the main result of (Qirjo et al., 2019), who provide robust and statistically significant evidence that suggest a negative relationship between the trade intensity and per capita emissions of GHGs due to the presence of CETA. The main result of this paper confirms the latter result for $\mathrm{CO}_{2}$, $\mathrm{CH}_{4}$, and $\mathrm{N}_{2} \mathrm{O}$, respectively. However, this is not the case for $H F C s / P F C s / S F_{6}$, where the

\footnotetext{
${ }^{1}$ See http://ec.europa.eu/trade/policy/in-focus/ceta/ceta-chapter-by-chapter/. Chapter 24 entitled "Trade and Environment" and chapter 22 entitled "Trade and Sustainable Development (TSD)" are the two chapters that deal with possible consequences of CETA on environment. On September, 13 2018, EU and Canadian committee members of TSD, have met to discuss progress on the procedure and institutional structures for the effective implementation of TSD chapters and exchange views on priority areas of trade and environment. For more details see http://trade.ec.europa.eu/doclib/docs/2018/september/tradoc_157409.pdf.
} 
results imply a positive, but mainly statistically insignificant, relationship between per capita emissions of $H F C s / P F C s / S F_{6}$ and trade intensity variable.

Qirjo et al. (2019) show that there is no shift of emissions per capita of GHGs between the EU and Canada due to the implementation of CETA. This is also the case for $\mathrm{CO}_{2}$, where we find that there is no statistically significant evidence of a positive relationship between per capita emissions of $\mathrm{CO}_{2}$ and the trade intensity variable between Canada and each EU member. It could be worth noting that in our dataset $75 \%$ of GHGs come from $\mathrm{CO}_{2}$ and the other three pollutants make in total only $25 \%$ of $G H G s$. However, the results of the present study show that the picture may seem pretty green for each CETA member when looking at either GHGs in general or $\mathrm{CO}_{2}$. However, this is not the case for $\mathrm{CH}_{4}, \mathrm{~N}_{2} \mathrm{O}$, and $H F C s / P F C s / S F_{6}$ despite the fact that per capita emissions of $\mathrm{CH}_{4}$ and $\mathrm{N}_{2} \mathrm{O}$ go down in a typical CETA member. The results of this paper suggest that there is a movement of emissions per capita of $H F C s / P F C s / S F_{6}\left(N_{2} O\right)$ from Canada towards a typical EU member (9 EU members) due to the implementation of CETA. There is also a shift of emissions per capita of $\mathrm{CH}_{4}$ from an average EU member towards Canada due to more trade between these two regions.

The current paper is analogous to Qirjo and Pascalau (2019b) and Qirjo and Pascalau (2019a) studies. These two latter studies empirically investigate the impacts of the potential Transatlantic Trade and Investment Partnership (TTIP) on several pollutants. They use a panel dataset of $28 \mathrm{EU}$ and the US during 1989-2013 time period. They provide statistically significant evidence indicating a negative (positive) relationship between the trade intensity variable and per capita emissions of $G H G s, \mathrm{CO}_{2}, \mathrm{~N}_{2} \mathrm{O}$, and $\mathrm{HFCs} / \mathrm{PFCs} / \mathrm{SF}_{6}$ $\left(\mathrm{SO}_{2}, S \mathrm{SO}_{\mathrm{x}}, \mathrm{NO}_{\mathrm{x}}, \mathrm{SF}_{6}\right.$, and $\left.\mathrm{NH}_{3}\right)$, respectively, for a typical EU member. Similar to the results of this study, the possible implementation of TTIP may help reduce per capita emissions of $\mathrm{GHGs}$ and $\mathrm{CO}_{2}$, but simultaneously may also help increase per capita emissions of other pollutants. The main difference between the empirical results of the current study to Qirjo and Pascalau (2019a) is that the implementation of CETA may help increase per capita emissions of $H F C s / P F C s / S F_{6}$ (however, this is mainly statistically insignificant), but the possible implementation of TTIP may help decrease per capita emissions of $H F C s / P F C s / S F_{6}$. Another difference between the latter paper and the current one, lies on the clear evidence of the presence of $\mathrm{PHH} 2$ due to the implementation of CETA, while the presence of PHH2 is less apparent in the case of TTIP. Note that either the US or Canada are sparsely populated, rich and capital-abundant as compared to a typical EU member. However, Canada is very sparsely populated than each EU member, while the US is sparsely populated than an average EU member (that are $3 \mathrm{EU}$ members that are more sparsely populated than the US). This latter fact could explain why Canada may act 
as pollution haven due to the implementation of CETA following PPH2, while this is less apparent in the case of the US as a results of a possible implementation of TTIP. Using an analogous intuition, one may also explain the clear evidence of the presence of FEH in the TTIP as reported in Qirjo and Pascalau (2019b). Something that is less apparent in the current study. Qirjo and Pascalau (2019b) show that there is a shift of emissions per capita of $\mathrm{GHGs}$ and $\mathrm{CO}_{2}$, respectively, from an average EU member towards the US, mainly because of $F E H$, due to the possible implementation of TTIP. However, this is not the case for Canada when focusing on these two air pollutants as a result of the implementation of CETA. This could be related to the fact that the US is much more capital-abundant as compared to an average EU member than there is Canada when compared to the same average EU member. Note that there are 13 EU members that are capital-abundant and 15 laborabundant EU members as compared to Canada, but there are only $3 \mathrm{EU}$ members that are capital-abundant as compared to the US (all the rest $25 \mathrm{EU}$ members are labor-abundant as compared to the US).

The rest of this paper is organized as follows. Section 2 describes the dataset and its sources, section 3 discusses the empirical results, and section 4 presents conclusions.

\section{Data Description of Air Pollutants and their Sources}

Carbon Dioxide is denoted by $\mathrm{CO}_{2}$. This is the most discussed and cited air pollutant from all GHGs in regards to climate change. In the sample, $\mathrm{CO}_{2}$ accounts for about $75 \%$ of all GHGs on average, for the EU and Canada during 1990 to 2016 time period. The unit of measurement for Carbon Dioxide is in Kiloton (Kt) per capita emissions. About $87 \%$ of the anthropogenic Carbon Dioxide emissions originate from the burning of fossil fuels such as coal, oil and natural gas. Approximately $10 \%$ of the anthropogenic $\mathrm{CO}_{2}$ emissions comes from the clearing of forests and other land use changes, and the rest of it originates from various industrial process, such as the manufacturing of cement.

Methane is denoted by $\mathrm{CH}_{4}$. The data for $\mathrm{CH}_{4}$ are expressed in $\mathrm{Kt}$ in $\mathrm{CO}_{2}$ equivalent per capita emissions. It is worth noting that despite the fact that $\mathrm{CH}_{4}$ 's lifetime in the atmosphere is much shorter than $\mathrm{CO}_{2}$, the comparative impact of the former air pollutant on climate change is about 25 times greater than the later air pollutant over a 100 years period. Also, note that almost $80 \%$ of methane originates from agriculture activities. The rest comes from waste from landfills, coal mining, and long-distance gas transmission.

The Fluorinated Gasses are denoted either by $H F C s / P F C s / S F_{6}$ or simply F-Gasses, where $H F C s$ stands for hydrofluorocarbons, $P F C s$ stands for perfluorocarbons, and $S F_{6}$ stands for 
Table 1: Data Sources of Air Pollutants and their unit of measurement

\begin{tabular}{|c|c|c|}
\hline Variable & Source & Unit of Measurement \\
\hline \hline $\mathrm{CO}_{2}$ (Carbon Dioxide) & UNFCCC (2019) & Kt per capita \\
\hline $\mathrm{CH}_{4}$ (Methane) & UNFCCC (2019) & $\mathrm{Kt}$ in $\mathrm{CO}_{2}$ equiv. per capita \\
\hline $\mathrm{HFCs} / \mathrm{PFCs} / \mathrm{SF}_{6}$ & UNFCCC (2019) & $\mathrm{Kt}$ in $\mathrm{CO}_{2}$ equiv. per capita \\
\hline $\mathrm{N}_{2} \mathrm{O}$ (Nitrous Oxide) & UNFCCC (2019) & $\mathrm{t}$ in $\mathrm{CO}_{2}$ equiv. per capita \\
\hline
\end{tabular}

sulfur hexafluoride. Note that the F-Gasses originate solely from human related activities and they are the most potent and longest lasted type of GHGs emitted by human activities. The major emissions source of HFCs is their application in refrigerators, or in air conditioning systems. PFCs are produced as a byproduct of several aluminum and/or manufacturing of semiconductor's industrial production processes. $S_{6}$ is the most potent of the F-Gasses in terms of its contribution to global warming. $S F_{6}$ is applied mainly in the various production processes of magnesium and/or electronics. HFCs/PFCs/SF 6 's unit of measurement is in $\mathrm{Kt}$ in $\mathrm{CO}_{2}$ equivalent per capita emissions.

Nitrous Oxide, also known as the laughing gas, is denoted by $\mathrm{N}_{2} \mathrm{O}$. The primary source of $\mathrm{N}_{2} \mathrm{O}$ from human activities originates from agriculture activities, primarily related to animal wastes, cultivation and fertilizers. It also comes from industrial activities related to manufacturing of nylon and nitric acid, and the burning of fossil fuels. Nitrous Oxide's unit of measurement is in tons ( $\mathrm{t}$ ) in $\mathrm{CO}_{2}$ equivalent per capita emissions.

The data for all of the above four air pollutants are obtained from UNFCCC (2019). Note that, the data for each of the four air pollutant is without LULUC. Table 2 reports a statistical description of the four exogenous, air pollution variables. It also shows a unit root (Im-Pesharan-Shin) test for each air pollutant, respectively. Each of the four air pollutant appears to be stationary when controlling simply for a trend, or a trend and its squared trend term, respectively. All the endogenous variables employed in this study are explained in the data section of Qirjo et al. (2019). See also their Table 2 for details on their statistical descriptions.

\section{Empirical Results}

The paper follows closely the empirical applications employed in Qirjo et al. (2019). The average impact of higher trade intensity between the EU and Canada on per capita emissions of $\mathrm{CO}_{2}, \mathrm{CH}_{4}, \mathrm{HFCs} / \mathrm{PFCs} / \mathrm{SF}_{6}$, and $\mathrm{N}_{2} \mathrm{O}$ are shown in Tables 4 through 7, respectively. Each of these Tables, reports the estimation results for all models and empirical methods employed in the study. The Column located furthers to the left presents the label of each of 
the endogenous variables. Columns (1), (2) and (3) show the results for the air pollutant when applying the fixed effects specification with robust heteroskedastic standard errors terms for models 1, 2 and 3, respectively. Columns (4), (5) and (6) report the results for the air pollutant when employing the random effects with robust heteroskedastic errors terms for models 1, 2 and 3, respectively. Columns (7), (8) and (9) indicate the results for the air pollutant when using the fixed effects specification controlling for robust crosssectional dependence standard errors terms for models 1, 2 and 3, respectively. Columns (10), (11) and (12) report the results for the air pollutant when applying the fixed effects method controlling for robust serial-correlation dependence (Driscoll-Kraay, under MA(2) component) standard errors terms for Models 1, 2 and 3, respectively.

Model 1 (M1) evaluates the role of trade intensity on pollution in the presence of PHH1 and FEH, but in the absence of PHH2. Model 2 (M2) looks at the role of trade intensity on pollution in the presence of $P H H 1, P H H 2$, and FEH. Model 3 (M3) tests the effect of trade intensity on pollution in the presence of $P H H 1, P H H 2$, and $F E H$, but also adds certain dummy variables that are closely related to the trade intensity variable (originating from the gravity and trade literature, such as use of the same official language, or common currency, or access to the sea). All three models also include a set of control variables such as: the three year moving average of income per capita (that we simply refer as income per capita); its squared value; the capital to labor ratio; the product of income per capita and capital to labor ratio; the inward FDI between Canada and each EU member to GDP ratio; land per capita; and its squared value. For more details, on each of the three econometric models see Qirjo et al. (2019).

The main variable of interest is the trade intensity variable labeled as Trade. This variable is constructed as the ratio of the volume of trade (sum of exports and imports) between each EU member and Canada to GDP. ${ }^{2}$ The trade intensity variable is reported in the $1^{\text {st }}$ row of Tables 4 through 7 . This variable along with its covariates is used to measure the overall impact of trade openness between the EU and Canada on each of the four air pollutants. The results reported in Table 4 show robust and strongly statistically significant evidence suggesting a negative relationship between the trade intensity variable and per capita emissions of $\mathrm{CO}_{2}$. This is an important result of this paper, since it shows that the presence of CETA could be along the forces that combat global warming, since CO2 is considered the most prominent anthropogenic air pollutant. This result is consistent with

\footnotetext{
${ }^{2}$ Mathematically, in the EU member $i$, the trade variable that is denoted with $T_{i}$, is constructed as: $T_{i}=$ $\frac{X_{i}+M_{i}}{G D P_{i}}$, where $X_{i}$ and $M_{i}$ denote the EU member's $i$ exports and imports to and from Canada, respectively. In the case of Canada (CAN), $T_{C A N}=\frac{X_{C A N}+M_{C A N}}{G D P_{C A N}}$, where $X_{C A N}=\sum_{i}^{28} M_{i}$ and $M_{C A N}=\sum_{i}^{28} X_{i}$ are all the exports and imports of Canada to and from the EU, respectively.
} 
Qirjo et al. (2019) where they analyze the impacts of GHGs in general in the presence of CETA. It is also consistent with Pascalau and Qirjo (2017a) or Qirjo and Pascalau (2019b), where they empirically analyze the impacts of TTIP on per capita emissions of GHGs and $\mathrm{CO}_{2}$, respectively. The current study finds positive but mainly statistically insignificant evidence of a positive relationship between the trade variable and the F-Gasses (see Table 7). The results of F-Gasses of the current study is contrary to those of Qirjo and Pascalau (2019a), where they show a generally negative and statistically significant relationship between the trade intensity variable and per capita emissions of the F-Gasses.

Despite the fact that Tables $5 \& 6$ show mixed and mainly statistical insignificant results of the role of trade on per capita emissions of $\mathrm{CH}_{4}$ and $\mathrm{N}_{2} \mathrm{O}$, respectively, the results of Tables $9 \& 10$ (where as explained later in this section, we look at the overall trade elasticity of each of these two pollutants) suggest a strong statistically significant evidence of a negative relationship between trade intensity and per capita emissions of $\mathrm{CH}_{4}$ and $\mathrm{N}_{2} \mathrm{O}$, respectively. Hence, overall, one may conclude that the main force behind the negative relationship between trade intensity and per capita emissions of GHGs as found in Qirjo et al. (2019) is related to the negative impact of trade intensity on per capita emissions of $\mathrm{CO}_{2}$ that it is shown in this study. Please note that $\mathrm{CO}_{2}$ consists of about 3/4 of all GHGs and the other three pollutants consist of only 1/4 of GHGs all together.

Results reported in the first row of Table 4, report that, on average, holding everything else constant, $1 \%$ increase of the volume of trade between each EU member and Canada as a portion of GDP, could help reduce annual per capita emissions of $\mathrm{CO}_{2}$ by about $244 \mathrm{Kt}$. This result is robust and statistically significant independent of the model or the empirical methodology used in the paper. Consequently, one may suggest that the presence of CETA could be associated with the race to top argument, implying that more trade between the $\mathrm{EU}$ and Canada is associated with an improvement of the national air pollution regulations for $\mathrm{CO}_{2}$ in trade members. In other words, the implementation of CETA could be an ally in fight against global warming in almost all CETA members because it may help reduce per capita emissions of $\mathrm{CO}_{2}$. The above results stand because of the combinations of PHH1, PHH2 and FEH in a typical EU member as a result of the presence of CETA. Note that an average EU member is labor-abundant, poor and extremely densely populated as compared to Canada. As reported in Table 3, there are $15 \mathrm{EU}$ members that are laborabundant, $17 \mathrm{EU}$ members that are rich, and none of the $\mathrm{EU}$ members is sparsely populated as compared to Canada.

The study uses the product of the trade intensity variable and relative capital to labor ratio, denoted by Trade $x R K L$, and its squared term to measure its diminishing returns, denoted by Trade $x(R K L)^{2}$, in order to capture FEH. The coefficients associated 
with these two variables are reported in the $2^{\text {nd }}$ and $3^{\text {rd }}$ rows of Tables $4-7$, respectively. The relative capital to labor ratio ( $R K L)$ is constructed relative to Canada (that in this case has a $R K L=1$ ). Thus, a capital-abundant (labor-abundant) EU member has a RKL $>1$ $(\mathrm{RKL}<1)$. Theoretically, consistent to $F E H$, the presence of CETA would increase air pollution in capital-abundant EU members, but reduce it in labor-abundant EU members. ${ }^{3}$ This is related to the application of the Heckscher-Ohlin theory and the empirical literature that suggests that capital-intensive goods pollute the environment more than the labor-intensive ones. ${ }^{4}$ Observing the signs of the slopes of Trade $x$ RKL and Trade $x(R K L)^{2}$, there is some limited evidence of the presence of FEH due to the implementation of CETA. This is more apparent for $\mathrm{CO}_{2}$ when using $\mathrm{M} 1$ under the fixed effects method with robust serial-dependence (Driscoll-Kraay) standard errors. For the other three pollutants, the estimates of Trade $x R K L$ are mainly positive but never statistically significant regardless of the model or empirical approach used in this paper.

The paper employs the cross-product of trade intensity and relative income per capita $(R I)$, denoted by Trade $x R I$, and its squared term, denoted by Trade $x(R I)^{2}$ to capture its diminishing returns, in order to measure PHH1. The slopes related to these two variables are reported in the $5^{\text {th }}$ and $6^{\text {th }}$ rows of Tables 4-7, respectively. $R I$ is built subject to Canada (thus, Canada has $R I=1$ ). Put it differently, a poor EU member has a $R I<1$, while a rich $\mathrm{EU}$ member has a $R I>1$. It is worth noting that in order to avoid the possible dual causality issue between income per capita $(I)$ and per capita emissions of each air pollutant, respectively (and also to avoid multicollinearity issues between per capita income and the trade intensity variable along with its covariates) $I$ is constructed as the three-year lagged moving average of real GDP per capita. ${ }^{5}$ Theoretically, PHH1 implies that poor countries adopt lax air pollution regulations and policies, and therefore, produce pollution-intensive goods, while rich countries adopt stringent air pollution policies, and thus, produce environmentally clean-intensive goods. ${ }^{6}$ Hence, a higher trade intensity between Canada and the poor EU due to the presence of CETA, may force the later EU members to act as pollution havens. Or, a higher trade intensity between Canada and the rich EU members, due to the presence of CETA, may force Canada to act as pollution haven. On average, observing

\footnotetext{
${ }^{3}$ See Antweiler et al. (2001), Davis and Caldeira (2010), Qirjo and Christopherson (2016), Qirjo and Pascalau (2019b), and Qirjo et al. (2019), who among others, provide empirical evidence consistent with FEH.

${ }^{4}$ There is plenty of empirical research that empirically validate the claim the capital-intensive goods are more pollution-intensive goods as compared to the labor-intensive ones (e.g., Jaffe et al. (1995), Cole and Elliott (2003)).

${ }^{5}$ Mathematically, we use the following weighting scheme when constructing the three-years lagged moving average of income per capita: $I_{i t}=.6 * I_{i t-1}+.3 * I_{i t-2}+.1 * I_{i t-3}$.

${ }^{6}$ See Levinson and Taylor (2008), Cole and Fredriksson (2009) and Qirjo and Pascalau (2019b) who among others, find empirical evidence in support of $P H H 1$.
} 
the signs of the coefficients of Trade $x R I$ and Trade $x(R I)^{2}$, there is some evidence over the presence of $\mathrm{PHH1}$. This is more apparent for $\mathrm{N}_{2} \mathrm{O}$ when using $\mathrm{M} 2 \& M 3$ under the fixed effects method with robust serial-dependence (Driscoll-Kraay) standard errors, and for the F-Gasses when using $M 1$ under the fixed effects method with robust serial-dependence (Driscoll-Kraay) standard errors. For $\mathrm{CO}_{2}$, the estimates of Trade $x \mathrm{RI}$ are never statistically significant regardless of the model or empirical approach used in this paper.

The study uses the cross-product of trade intensity and relative land per capita (RLPC), denoted by Trade $x$ RLPC, and its squared term, denoted by Trade $x(R L P C)^{2}$ to measure its diminishing returns, in order to capture $\mathrm{PHH} 2$. The coefficients of the later two variables are reported in the $11^{\text {th }}$ and $12^{\text {th }}$ rows of Tables 4-7, respectively. The $R L P C$ of each EU member is expressed relative to Canada (Thus, Canada has $R L P C=1$ ). Since every EU member is more densely populated relative to Canada, each EU member's RLPC is less than 1. PHH2 argues that the presence of CETA may reallocate the production of pollution intensive goods from densely populated EU members towards the very sparsely populated Canada. Therefore, Canada may act as pollution haven due to the implementation of CETA. ${ }^{7}$ The signs of Trade $x$ RLPC and Trade $x(R L P C)^{2}$ suggest evidence in accordance to PHH2 for three air pollutants. In particular, for $\mathrm{CO}_{2}$, the estimates of Trade $x$ RLPC are positive and statistically significant only under $M 2$ when using the simple fixed effects or the random effects or the fixed effects with cross sectional dependence standard error terms techniques. In the case of $\mathrm{N}_{2} \mathrm{O}$, the estimates of Trade $x$ RLPC are positive and statistically significant only under $M 2 \& M 3$ when using the simple fixed effects or the random effects or the fixed effects with cross sectional dependence standard error terms techniques, and when using $M 3$ under the fixed effects method with robust serial-dependence (DriscollKraay) standard errors. In the case of the F-Gasses, the estimates of Trade $x$ RLPC are positive and statistically significant only under $M 2 \& M 3$ when using the simple fixed effects or the fixed effects with cross sectional dependence standard error terms or the fixed effects with robust serial-dependence (Driscoll-Kraay) standard errors techniques. Consequently, on average, EU members that are more densely populated tend to decrease per capita emissions of $\mathrm{CO}_{2}, \mathrm{~N}_{2} \mathrm{O}$, and the F-Gasses, respectively, as they increase their trade intensity levels with Canada. In other words, the implementation of CETA may help increase per capita emissions of $\mathrm{CO}_{2}, \mathrm{~N}_{2} \mathrm{O}$, and the F-Gasses, respectively, in Canada since the latter trade member is more sparsely populated than any EU member. Hence, Canada may act as a pollution haven due to the presence of CETA for these three air pollutants.

\footnotetext{
${ }^{7}$ Frankel and Rose (2005) was the first empirical study to evaluate the possible presence of PHH2. Qirjo and Pascalau (2019b) and Qirjo et al. (2019) find some empirical evidence consistent with PHH2 in the cases of TTIP and CETA, respectively.
} 
Following the work of Antweiler et al. (2001), this study builds trade elasticities in order to measure the overall impact of the trade intensity variable on per capita emissions of each pollutant, not only in total (as an average) but also in each CETA member (see also the analogous Table 4 of Qirjo et al. (2019) in the case of GHGs in general). The slopes of these trade elasticities are reported in Tables 8-11, where each CETA member is listed alphabetically in the furthest left column. The last row of each of Tables 8-11, reports the trade elasticity coefficients in a typical CETA member. Columns (1), (2) and (3) show the trade elasticities when employing $M 1$ under fixed effects, random effects, and fixed effects with cross-sectional dependence robust standard errors, respectively. Note that, Tables 8-11 do not report the trade elasticities associated with the fixed effects with serial-correlation (Driscoll-Kraay) robust standard errors because they are extremely similar to those under fixed effects with cross-sectional dependence robust standard errors for any model used in the paper. Columns (4), (5) and (6) show the trade elasticities when employing $M 2$ under fixed effects, random effects, and fixed effects with cross-sectional dependence robust standard errors, respectively. Finally, columns (7), (8) and (9) show the trade elasticities when employing $M 3$ under fixed effects, random effects, and fixed effects with cross-sectional dependence robust standard errors, respectively. All the results reported in Tables 8-11 are in percentage points.

Each trade elasticity is constructed using the Delta method. In Table 8, each of them shows exactly how much does per capita emissions of $\mathrm{CO}_{2}$ change when the ratio of the volume of trade to GDP increases by .0001 . The study uses such small changes because the average value of the trade intensity variable in the sample is about .057\%. As expected, there is statistically significant evidence (however, it is not statistically significant only when using $M 2$, or when employing $M 3$ only under random effects), suggesting that an increase of $0.01 \%$ of the ratio of trade between a typical EU member and Canada to GDP, could help reduce annual per capita emissions of $\mathrm{CO}_{2}$, in an average CETA member, by about $.476 \%$. It is worth noting that according to the results reported in Table 8 , there is no CETA member that has a positive and statistically significant trade elasticity slope with the exception of Finland, where it is positive and statistically significant only when using M2 under random effects. This result indicates that there is no statistically significant evidence that the presence of CETA may increase per capita emissions of $\mathrm{CO}_{2}$ in some CETA member even though, it decreases them on average. In other words, there is no statistically significant evidence supporting the argument that there could be a shift of $\mathrm{CO}_{2}$ per capita emissions between trade partners due to the presence of CETA.

The results of Table 8 , show that trade elasticities are mainly negative for most CETA members, with the exceptions of Canada, Finland and Slovenia (however, for the later 3 
countries, they are not statistically significant). In the cases, of Belgium, Bulgaria, Czech Republic, Hungary, Luxembourg, Malta, Poland, Romania, Spain, and the UK trade elasticity coefficients are negative and generally strongly statistically significant. The results of Table 8 also point out that despite the fact that trade elasticities are mainly negative, they are mainly not statistically significant for Austria, Cyprus, Denmark, Germany, Greece, Italy, the Netherlands, Portugal, Slovakia, Slovenia, and Sweden.

Note that $M 1$ evaluates the effects of trade intensity between trade members on air pollution only in the presence of $P H H 1$ and FEH along with the control variables. M2 in addition to all variables used in $M 1$, introduces $P H H 2$. Thus, it could be important to compare the trade elasticities of $M 1$ to those of $M 2$ in terms of their magnitude, sign and statistically significance. Remember that Canada is very sparsely populated as compared to each EU member. Thus, according to $\mathrm{PHH}$, Canada may adopt lax environmental regulations when trading more with each EU member. Therefore, per capita emissions of $\mathrm{CO}_{2}$ may increase in Canada due to the presence of CETA. Looking at the signs of trade elasticities for Canada when using $M 1$ as compared to those when using $M 2$, it is apparent that trade elasticities become positive under $M 2$, while they were negative under $M 1$ for every empirical method used in the study. However, they are never statistically significant for any model or empirical specification used in the study. Comparing the trade elasticities of $M 1$ to those of $M 2$, it could be worth noting that they become higher in absolute value (remaining negative) under the later model as compared to the former one, for Belgium and Luxembourg. This could imply that higher trade between Canada and each of the later two EU members could force them to stringent their air policy regulations even further following $\mathrm{PHH} 2$, and therefore, reduce per capita emissions of $\mathrm{CO}_{2}$ even more.

Focusing on the trade elasticities coefficients associated solely to $M 1$, it turns out that there is statistically significant evidence suggesting that FEH dominates PHH1 for Bulgaria, Croatia, Estonia, Hungary, Latvia, Lithuania, Malta, Poland, and Romania, respectively. This is related to the fact that each of the later EU members is labor-abundant and poor as compared to Canada. Thus, theoretically one can not predict the effects of higher trade intensity between these EU members and Canada on air pollution. This is because the later EU members would produce more labor-intensive goods following $F E H$, but at the same time, they have lax air pollution regulations as compared to Canada following PHH1. However, the negative and strong statistically significant trade elasticities indicate that in each of the later EU members, being labor-abundant is more important than being poor in reducing air pollution due to higher trade between them and Canada.

It appears that Luxembourg is the only rich and capital-abundant EU member, where there is statistically significant evidence suggesting that PHH1 dominates FEH. In other 
words, Luxembourg reduces per capita emissions of $\mathrm{CO}_{2}$ due to higher trade intensity with Canada because being rich for the later EU member seems more important than being capital-abundant. In other $7 \mathrm{EU}$ members that are rich and capital-abundant, all trade elasticities are negative, but they are never statistically significant, respectively, regardless of the empirical method used in the paper. This suggests that in the later EU members PHH1 cancels out FEH. It turns out that there is no evidence supporting the argument that per capita emissions of $\mathrm{CO}_{2}$ would increase in each capital-abundant but poor EU member due to the presence of CETA, along the lines of FEH and PHH1. Table 8, reports negative trade elasticities for each rich and labor-abundant EU member confirming the argument that per capita emissions of $\mathrm{CO}_{2}$ should decrease in the later EU members due to the presence of CETA. However, they are never statistically significant under each empirical specification used in the study. Finally in the case of Canada, it appears that under $M 1$, all coefficients of trade elasticities are negative. However, they are never statistically significant. Therefore, since Canada is capital-abundant and rich as compared to a typical EU member, it should be that $P H H 1$ cancels out FEH.

Comparing the trade elasticities of $\mathrm{CO}_{2}$ reported in Table 8 of this study to the analogous trade elasticities of GHGs presented in Table 4 of Qirjo et al. (2019), it is worth noting the similarities and differences between them. Both Tables indicate robust and statistically significant evidence suggesting, on average, a negative relationship between per capita emissions of each of the latter two air pollutants and the trade intensity variable. However, trade elasticities associated with GHGs are higher in magnitude and always statistically significant, regardless of the model or empirical specification used in the study, as compared to trade elasticities of $\mathrm{CO}_{2}$. Moreover, it appears that trade elasticities are generally negative in each EU member (with the exception of Finland that is positive but not statistically significant), but they are mainly statistically significant only in $8 \mathrm{EU}$ members for each of the two air pollutants. In the case of Canada, they are generally positive, but never statistically significant. In the case of GHGs, trade elasticities are negative and generally statistically significant for 8 Western European EU members, where 5 of them are capital-abundant and rich, 1 is labor-abundant and rich, 1 is labor-abundant but poor, and 1 is capital-abundant but poor. While, in the case of $\mathrm{CO}_{2}$, trade elasticities are negative and mainly statistically significant for 4 Ex-Communist EU members and 4 Western EU members, where 5 of them are labor-abundant and poor, 2 are capital-abundant and rich, and 1 is capital-abundant but poor. The latter two results imply that in the case of GHGs, one of the main reasons why per capita emissions of GHGs go down in the presence of CETA, could be because the rich EU members may adopt stringent air pollution regulation and policies, despite of being capital-abundant, while Canada simultaneously does 
not drop them due to the presence of CETA. On the other hand, in the case of $\mathrm{CO}_{2}$, the main reason why per capita emissions of $\mathrm{CO}_{2}$ go down, could be related to the fact that more capital-intensive goods are produced in rich but capital-abundant Canada, while more labor-abundant goods are produced in labor-abundant and poor EU members due to higher trade intensity between the EU and Canada. In other words, per capita emissions of $\mathrm{CO}_{2}$ go down because the production of capital-intensive goods move from the poor EU members (mainly Ex-Communist EU members) into rich Canada that may use more environmental friendly technologies than the latter EU members.

Table 9 presents the trade elasticities for each CETA member and the average total trade elasticities for a typical CETA member in the case of $\mathrm{CH}_{4}$. Similarly to the results of Table 8, the results of Table 9 show strongly statistically significant evidence, regardless of the model or empirical technique used in this study, implying that an increase of $0.01 \%$ of the volume of trade between a typical EU member and Canada to GDP ratio, could help reduce annual per capita emissions of $\mathrm{CH}_{4}$, in a typical CETA member, by about .65\%. It is worth noting that according to the results reported in Table 9, contrary to the results of Table 8, there are several CETA member that have positive and statistically significant trade elasticity slopes. These CETA members are Bulgaria (where the trade elasticity coefficients are positive and statistically significant only under $M 3$ when employing the fixed and random effects methodologies), Canada (where the trade elasticity coefficients are positive and statistically significant under $M 2 \& M 3$ regardless of the empirical techniques used in the study), Hungary (where the trade elasticity coefficients are positive and statistically significant only under $M 3$ when employing the fixed effects with the cross-sectional dependence of the robust standard error terms methodology), Malta (where the trade elasticity coefficients are positive and statistically significant under $M 1$ when employing the fixed and random effects methodologies and under $M 2$ regardless of the empirical technique used in the paper), Poland (where the trade elasticity coefficients are positive and statistically significant under $M 2 \& M 3$ regardless of the empirical techniques used in the study), Romania (where the trade elasticity coefficients are positive and statistically significant only under M3 when employing the simple fixed effects methodology), and Spain (where the trade elasticity coefficients are positive and statistically significant only under $M 3$ when employing the fixed effects with the cross-sectional dependence of the robust standard error terms methodology). These results indicate that there is statistically significant evidence that the presence of CETA increases per capita emissions of $\mathrm{CH}_{4}$ in these CETA members, despite the fact that the implementation of CETA decreases per capita emissions of $\mathrm{CH}_{4}$ in an average CETA member. In other words, there is statistically significant evidence supporting the argument that there could be a shift of $\mathrm{CH}_{4}$ per capita emissions between trade partners 
due to the presence of CETA.

The results of Table 9, show that trade elasticities are mainly negative for most CETA members, with the exceptions of countries mentioned in the previous paragraph. In particular, for Austria, Belgium, Cyprus, Czech Republic, Finland, France, Greece, Ireland, Italy, Lithuania, Luxembourg, Portugal, Slovakia, Slovenia, and Sweden trade elasticity coefficients are negative and generally strongly statistically significant. The results of Table 9 also point out that despite the fact that trade elasticities are mainly negative, they are mainly not statistically significant for Estonia, the Netherlands, and the UK.

In order to see the potential of Canada acting as a pollution haven following PHH2 argument due to the implementation of CETA, it could be important to compare the trade elasticities of $M 1$ to those of $M 2$ in terms of their magnitude, sign and statistically significance. Note that Canada is very sparsely populated as compared to each EU member. Thus, according to $\mathrm{PHH}$, Canada may adopt lax environmental regulations when trading more with each EU member. Therefore, per capita emissions of $\mathrm{CH}_{4}$ may increase in Canada due to the presence of CETA. Looking at the signs of trade elasticities for Canada when using $M 1$ as compared to those when using $M 2$, it is apparent that trade elasticities become positive and strongly statistical significant under $M 2(\& M 3)$, regardless of the empirical methodology used in this paper, while they are negative, but not statistically significant under $M 1$ for every empirical method used in the study. This is an important finding because it suggests that in the case of $\mathrm{CH}_{4}$, Canada may act as pollution haven when trading more with the EU because it is very sparsely populated as compared to each EU member. In Canada for $\mathrm{CH}_{4}, \mathrm{PHH} 2$ strongly dominates $\mathrm{PHH}$. In other words, for Canada being more densely populated dominates being rich, and therefore, one observes higher per capita emissions of $\mathrm{CH}_{4}$, when Canada trades more with the EU forcing to former trade partner to act as pollution haven. Comparing the trade elasticities of $M 1$ to those of $M 2$, it could be worth noting that they become higher in absolute value (remaining negative) under the later model as compared to the former one, for Austria, Belgium, Cyprus, Czech Republic, Finland, France, Greece, Ireland, Italy, Lithuania, Luxembourg, Portugal, Slovakia, Slovenia, and Sweden. This could imply that higher trade between Canada and each of these $15 \mathrm{EU}$ members could force them to stringent their air policy regulations even further following $\mathrm{PHH} 2$, and therefore, reduce per capita emissions of $\mathrm{CH}_{4}$ even more. These results indicate that an important reason why Canada may act as pollution haven for $\mathrm{CH}_{4}$, when trading more with the latter $15 \mathrm{EU}$ members is related to the fact that Canada is very sparsely populated as compared to each of these $15 \mathrm{EU}$ members. Put it differently, $\mathrm{PHH} 2$ shifts pollution of $\mathrm{CH}_{4}$ towards Canada as a result of trading more with each of the latter EU members. 
It appears that Austria, Belgium, Finland, France, and Luxembourg are the only rich and capital-abundant EU members, where there is statistically significant evidence suggesting that $\mathrm{PHH} 1$ dominates $\mathrm{FEH}$. In other words, these $5 \mathrm{EU}$ members reduce per capita emissions of $\mathrm{CH}_{4}$ due to higher trade intensity with Canada, respectively, because being rich for each of the later $5 \mathrm{EU}$ members seems more important than being capital-abundant. It turns out that similar to the case of $\mathrm{CO}_{2}$, there is no evidence supporting the argument that per capita emissions of $\mathrm{CH}_{4}$ would increase in each capital-abundant but poor EU member due to the presence of CETA, along the lines of FEH and PHH1. Looking at the estimates under $M 1$, Table 9 reports negative and statistically significant trade elasticities for Ireland that is richer and labor-abundant EU member as compared to Canada. This finding supports the theoretical argument that the implementation of CETA should decrease pollution in labor abundant and rich trade members following by the combination of FEH and $P H H 1$. However, there is no empirical evidence suggesting that the latter theory is true for the other $2 \mathrm{EU}$ members (the Netherlands and the UK) that are also richer and labor-abundant as compared to Canada.

Comparing the trade elasticities of $\mathrm{CH}_{4}$ reported in Table 9 of this study to the analogous trade elasticities of GHGs presented in Table 4 of Qirjo et al. (2019), one can see the similarities and differences between them. Both Tables indicate robust and statistically significant evidence, regardless of the model or empirical specification used in the study, suggesting on average, a negative relationship between per capita emissions of each of these 2 air pollutants and the trade intensity variable. However, trade elasticities associated with GHGs are lower in magnitude as compared to trade elasticities of $\mathrm{CH}_{4}$. Moreover, it appears that trade elasticities for GHGs are generally negative (and statistically significant for most EU members) in each EU member, but they are never positive and statistically significant for any CETA member. On the other hand, in the case of $\mathrm{CH}_{4}$, Table 9, reports positive and statistically significant trade elasticity estimates for Bulgaria, Canada, Hungary, Malta, Poland, Romania, and Spain. The case of Canada is important because it suggests that there is a shift of emissions per capita of $\mathrm{CH}_{4}$ from most EU members towards Canada due to more trade between these trade partners. Something that is never the case for GHGs. Table 9 presents solid statistical evidence in support of $\mathrm{PHH}_{2}$ for $\mathrm{CH}_{4}$, that is not that apparent (at least not statistically significant) for GHGs.

Table 10 presents the trade elasticities for each CETA member and the average total trade elasticities for a typical CETA member in the case of $\mathrm{N}_{2} \mathrm{O}$. Similarly to the results of Tables $8 \& 9$, the results of Table 10 show strongly statistically significant evidence, regardless of the model or empirical technique used in this study, implying that an increase of $0.01 \%$ of the volume of trade between a typical EU member and Canada to 
GDP ratio, could help reduce annual per capita emissions of $N_{2} \mathrm{O}$, in a typical CETA member, by about $1.2 \%$. It is worth noting that according to the results reported in Table 10, there are several CETA member that have positive and statistically significant trade elasticity slopes. These CETA members are Bulgaria (where the trade elasticity coefficients are positive and statistically significant only under $M 2$ when employing the fixed and random effects methodologies), Croatia (where the trade elasticity coefficients are positive and statistically significant under $M 2$, regardless of the empirical techniques used in the study), Estonia (where the trade elasticity coefficients are positive and statistically significant under $M 2 \& M 3$, regardless of the empirical techniques used in the study), Hungary (where the trade elasticity coefficients are positive and statistically significant only under M2 when employing the simple fixed effects and the fixed effects with the cross-sectional dependence of the robust standard error terms methodologies), Latvia (where the trade elasticity coefficients are positive and statistically significant under $M 2$, regardless of the empirical technique used in the paper and under $M 3$ when employing the fixed and random effects methodologies), Lithuania (where the trade elasticity coefficients are positive and statistically significant under $M 2 \& M 3$ regardless of the empirical techniques used in the study), Poland (where the trade elasticity coefficients are positive and statistically significant under $M 2$ when employing the fixed and random effects methodologies), Romania (where the trade elasticity coefficients are positive and statistically significant under M2 when employing the fixed and random effects methodologies), and Spain (where the trade elasticity coefficients are positive and statistically significant under $M 2$, regardless of the empirical techniques used in the study). These results indicate that there is statistically significant evidence that the presence of CETA increases per capita emissions of $\mathrm{N}_{2} \mathrm{O}$ in these EU members, despite the fact that the implementation of CETA decreases per capita emissions of $\mathrm{N}_{2} \mathrm{O}$ in an average CETA member. Consequently, there is statistically significant evidence supporting the argument that there could be a shift of $\mathrm{N}_{2} \mathrm{O}$ per capita emissions from Canada towards these $9 \mathrm{EU}$ members due to the presence of CETA.

The results of Table 10, show that trade elasticities of $\mathrm{N}_{2} \mathrm{O}$ are mainly negative for most CETA members, with the exceptions of countries mentioned in the previous paragraph. In particular, for Austria, Belgium, Canada, Cyprus, Czech Republic, Denmark, France, Germany, Greece, Ireland, Italy, Luxembourg, the Netherlands, Portugal, Slovakia, Slovenia, and the UK trade elasticity coefficients are negative and generally strongly statistically significant. It could be worth noting that this result in Canada could be true because PHH1 dominates $F E H$. This is because Canada is rich and capital-abundant as compared to a typical EU member. The empirical results of Table 10 imply that, for Canada, being rich is more important than being capital-abundant in order to reduce per capita emissions of 
$\mathrm{N}_{2} \mathrm{O}$ due to more trade with the EU. Using the same intuition, one may note that the above results could be true in Austria, Belgium, Denmark, France, Germany, and Luxembourg because $P H H 1$ dominates FEH. Note that each of these $6 \mathrm{EU}$ members are rich and capitalabundant as compared to Canada. Analogously to Canada, the empirical results of Table 10 imply that, for each of these $6 \mathrm{EU}$ members, being rich is more important than being capital-abundant in order to reduce per capita emissions of $\mathrm{N}_{2} \mathrm{O}$ due to more trade with Canada. The results of Table 10 also indicate that although trade elasticities are mainly negative, they are mainly not statistically significant for Finland, Malta, and Sweden.

Comparing the trade elasticities of $M 1$ to those of $M 2$ in terms of their magnitude, sign and statistically significance, there is some weak empirical evidence in support of $P H H 2$. Remember that Canada is very sparsely populated as compared to each EU member. Thus, according to $\mathrm{PHH}$, Canada may adopt lax environmental regulations when trading more with each EU member. Therefore, per capita emissions of $\mathrm{N}_{2} \mathrm{O}$ may increase in Canada due to the presence of CETA. Looking at the statistically significance of trade elasticities for Canada when using $M 1$ as compared to those when using $M 2$, it is apparent that trade elasticities become statistically insignificant under M2 (however, they are still negative) when using fixed and random effects techniques, while they are statistically significant and negative under $M 1$, regardless of the empirical methodology used in the study. Comparing the trade elasticities of $M 1$ to those of $M 2$, it could be worth noting that they become higher in absolute value (remaining negative) under the later model as compared to the former one, for Austria, Belgium, Denmark, Germany, Italy, Luxembourg, and the Netherlands. This could imply that higher trade between Canada and each of these $7 \mathrm{EU}$ members could force them to stringent their air policy regulations even further following $\mathrm{PHH} 2$, and therefore, reduce per capita emissions of $\mathrm{N}_{2} \mathrm{O}$ even more than it is explained via the $\mathrm{PHH} 1$ channel.

It appears that contrary to the cases of $\mathrm{CO}_{2}$ and $\mathrm{CH}_{4}$, there is some empirical evidence supporting the theoretical argument that per capita emissions of $\mathrm{N}_{2} \mathrm{O}$ would increase in capital-abundant but poor EU members due to the presence of CETA, following the channels of FEH and PHH1. However, this is true only for Spain, but it is not the case for Cyprus, Czech Republic, Greece, and Italy. Looking at the estimates under M1, Table 10 reports negative and statistically significant trade elasticities for Ireland, the Netherlands, and the UK that are each richer and labor-abundant EU member as compared to Canada. This finding supports the theoretical argument that the implementation of CETA should decrease pollution in labor abundant and rich trade members following by the combination of $F E H$ and $P H H 1$.

Comparing the trade elasticities of $\mathrm{N}_{2} \mathrm{O}$ reported in Table 10 of this study to the anal- 
ogous trade elasticities of GHGs presented in Table 4 of Qirjo et al. (2019), one can see the similarities and differences between them. Both Tables indicate robust and statistically significant evidence, regardless of the model or empirical specification used in the study, suggesting on average, a negative relationship between per capita emissions of each of these 2 air pollutants and the trade intensity variable. However, trade elasticities associated with $G H G s$ are lower in magnitude as compared to trade elasticities of $\mathrm{N}_{2} \mathrm{O}$. Moreover, it appears that trade elasticities for GHGs are generally negative (and statistically significant for most EU members) in each EU member, but they are never positive and statistically significant for any CETA member. However, for $\mathrm{N}_{2} \mathrm{O}$, Table 10, reports positive and statistically significant trade elasticity estimates for Bulgaria, Croatia, Estonia, Hungary, Latvia, Lithuania, Poland, Romania, and Spain. The latter result suggests that for $\mathrm{N}_{2} \mathrm{O}$, there is a shift of pollution from Canada towards these $9 \mathrm{EU}$ members due to more trade between these trade partners. In other words, this result implies that these $9 \mathrm{EU}$ members would act as pollution haven when trading more with Canada because they are poor despite of being labor-abundant (with the exception of Spain that is poor and capital-abundant). Hence, this result validates the empirical validity of $\mathrm{PHH} 1$ for these EU members (with the exception of Spain) in the case of $\mathrm{N}_{2} \mathrm{O}$. This is never the case for GHGs.

Table 11 presents the trade elasticities for each CETA member and the average total trade elasticities for a typical CETA member in the case of F-Gasses. Contrary to the results of Tables $8,9, \& 10$ the results of Table 10 indicate no statistically significant evidence (with the exception of the use of $M 2$ under the fixed effects with cross-sectional dependence robust standard errors, where there is positive and statistically significant evidence of the average total trade elasticity coefficient) implying that an increase of $0.01 \%$ of the volume of trade between a typical EU member and Canada to GDP ratio, could help increase annual per capita emissions of F-Gasses, in a typical CETA member, by about $0.73 \%$. It is worth noting that according to the results reported in Table 11, there are several CETA member that have negative and statistically significant trade elasticity slopes. These CETA members are Austria (where the trade elasticity coefficients are negative and statistically significant under $M 1$ when employing the fixed effects with cross-sectional dependence robust standard errors technique, and under M3 when using the random effects technique), Belgium (where the trade elasticity coefficients are negative and statistically significant under $M 1$, regardless of the empirical technique used in the paper, and under $M 2$ when employing the fixed effects with cross-sectional dependence robust standard errors technique, and under $M 3$ when using the random effects and the fixed effects with cross-sectional dependence robust standard errors methodologies), Canada (where the trade elasticity coefficients are negative and statistically significant under $M 1 \& M 2$ when employing the fixed effects with 
cross-sectional dependence robust standard errors technique), Cyprus (where the trade elasticity coefficients are negative and statistically significant under $M 1$ when employing the simple fixed effects and the fixed effects with cross-sectional dependence robust standard errors methodologies, and under $M 3$, regardless of the empirical technique used in the study), Czech Republic, France, Germany, the Netherlands, Slovakia (where the trade elasticity coefficients for each of these $5 \mathrm{EU}$ members are negative and statistically significant only under $M 3$ when employing the random effects methodology), Greece (where the trade elasticity coefficients are negative and statistically significant under $M 3$, regardless of the empirical technique used in the paper), Italy (where the trade elasticity coefficients are negative and statistically significant regardless of the model and empirical technique used in the paper with the exception of $M 2$ under fixed effects technique), Portugal, Slovenia (where the trade elasticity coefficients in each of these $2 \mathrm{EU}$ members are negative and statistically significant under $M 3$ when using random effects and fixed effects with crosssectional dependence robust standard errors methodologies), and the UK (where the trade elasticity coefficients are negative and statistically significant under $M 3$ when employing the random effects). These results indicate that there is statistically significant evidence that the presence of CETA decreases per capita emissions of F-Gasses in these 14 EU members, despite the fact that the implementation of CETA increases per capita emissions of F-Gasses in an average CETA member.

The results of Table 11, show that trade elasticities of F-Gasses are mainly positive for the rest of the EU members that are not mentioned in the previous paragraph. In particular, for Bulgaria, Croatia, Estonia, Finland, Hungary, Latvia, Lithuania, Malta, Poland, Romania, Spain, and Sweden trade elasticity coefficients are positive and generally strongly statistically significant. It could be worth noting that for the former Communist EU members (such as Bulgaria, Croatia, Estonia, Hungary, Latvia, Lithuania, Poland, and Romania) this result may stand because being poor is more important than being labor-abundant in order to increase per capita emissions of F-Gasses due to more trade with the EU. Remember that all these former Communist EU members are poorer and labor-abundant as compared to Canada, and therefore, the above results suggests that in these EU members PHH1 dominates FEH. In other words, the implementation of CETA could help shift F-Gasses from Canada towards each of these former Communist EU members. Using the same intuition, one may note that the above results could be true in Malta because PHH1 dominates FEH. However, the opposite is true for EU members that are rich and capital-abundant as compared to Canada. Here, there are $2 \mathrm{EU}$ members with these characteristics, Finland and Sweden. Hence, the empirical results of Table 11 imply that, for each of these $2 \mathrm{EU}$ members, being capital-abundant is more important than being rich for increasing per capita 
emissions of F-Gasses due to more trade with Canada. Thus, in Finland and Sweden FEH dominates PHH1. The results of Table 10 also indicate that although trade elasticities are mainly positive, they are mainly not statistically significant for Ireland and Luxembourg.

Comparing the trade elasticities of $M 1$ to those of $M 2$ in terms of their magnitude, sign and statistically significance, there is no empirical evidence in support of $\mathrm{PHH} 2$ for the F-Gasses. It appears that similar to $\mathrm{N}_{2} \mathrm{O}$, there is some empirical evidence supporting the theoretical argument that per capita emissions of $F$-Gasses would increase in a capitalabundant but poor EU member due to the presence of CETA, following the channels of FEH and $P H H 1$. The results of Table 11 empirically validate the latter theoretical claim only for Spain. However, this is not true for Cyprus, Czech Republic, Greece, and Italy. Looking at the estimates under $M 1$, Table 11 reports no statistically significant evidence in support of the theoretical argument that the implementation of CETA should decrease per capita emissions of F-Gasses in labor abundant and rich EU members (as compared to Canada) following by the combination of FEH and PHH1.

Comparing the trade elasticities of F-Gasses reported in Table 11 of this study to the analogous trade elasticities of GHGs presented in Table 4 of Qirjo et al. (2019), one can see the similarities and differences between them. The main contrast between the results reported in these 2 Tables is that the results of Table 11 show a positive relationship (however, mainly statistically insignificant) between per capita emissions of F-Gasses and the trade intensity variable. However, the results of Table 4 of Qirjo et al. (2019) indicate robust and statistically significant evidence, regardless of the model or empirical specification used in their study, implying on average, a negative relationship between per capita emissions of GHGs and the trade intensity variable. However, for F-Gasses, Table 11, similar to Table 4 of Qirjo et al. (2019) for GHGs, reports negative and statistically significant trade elasticity estimates for Belgium, Cyprus, and Italy. The results of Table 11 suggest that the implementation of CETA could help shift F-Gasses from Canada towards some former Communist EU members (such as Bulgaria, Croatia, Estonia, Hungary, Latvia, Lithuania, Poland, and Romania). This movement of F-Gasses from Canada towards these $8 \mathrm{EU}$ members could be because these $8 \mathrm{EU}$ members would act as pollution haven when trading more with Canada since they are poor despite of being labor-abundant. Hence, this result validates the empirical validity of $\mathrm{PHH} 1$ for these 8 former Communist EU members in the case of F-Gasses. There is no shift of GHGs from Canada towards any EU members. as reported in Table 4 of Qirjo et al. (2019).

Comparing the results of trade elasticities of the 4 air pollutants as reported in Tables 8-11, it could be worth pointing out the main similarities and differences among them. Looking at Tables, 8-10, it appears that there is negative and statistically significant evi- 
dence of the relationship between the trade intensity variable and per capita emissions of $\mathrm{CO}_{2}, \mathrm{CH}_{4}$, and $\mathrm{N}_{2} \mathrm{O}$, respectively. It seems that on average, in absolute value, trade elasticities of $\mathrm{N}_{2} \mathrm{O}$ are higher than those of $\mathrm{CH}_{4}$ and the latter are higher than those of $\mathrm{CO}_{2}$. In other words, the implementation of CETA may help bring down per capita emissions of $\mathrm{N}_{2} \mathrm{O}$ more than it can help decrease per capita emissions of $\mathrm{CH}_{4}$ or $\mathrm{CO}_{2}$. Contrary to the results reported in Tables $9 \& 10$, the results of Table 8 show that there is no statistically significant evidence that per capita emissions of $\mathrm{CO}_{2}$ would increase in any CETA member as a result of more trade between Canada and the EU. The results reported in Tables $9 \&$ 10, show that despite the fact that per capita emissions of $\mathrm{CH}_{4}$, and $\mathrm{N}_{2} \mathrm{O}$ would go down due to the implementation of CETA in a typical CETA member, this is not the case for each CETA member. In particular, there is a statistically significant evidence suggesting that more trade between Canada and the EU may help increase per capita emissions of $\mathrm{CH}_{4}$ for Bulgaria, Canada, Hungary, Malta, Poland, Romania, and Spain. There is a statistically significant evidence implying that the implementation of CETA may help increase per capita emissions of $\mathrm{N}_{2} \mathrm{O}$ for Bulgaria, Croatia, Estonia, Hungary, Latvia, Lithuania, Poland, Romania, and Spain. Contrary to the results reported in Tables 8-10, the results of Table 11 show a positive, but mainly statistically insignificant relationship between the trade intensity variable and per capita emissions of F-Gasses. The results of Table $9 \mathrm{im}-$ ply that there is empirical evidence in support of $\mathrm{PHH} 2$ in the case of Canada for $\mathrm{CH}_{4}$. Therefore, Canada would act as pollution haven when trading more with the EU for $\mathrm{CH}_{4}$ simply because it is more densely populated than any EU members. Put it differently, the implementation of CETA may help move per capita emissions of $\mathrm{CH}_{4}$ and $\mathrm{CO}_{2}$ from the EU towards Canada. The results of Tables $10 \& 11$ suggest that there is empirical evidence in support of $\mathrm{PHH} 1$ for $\mathrm{N}_{2} \mathrm{O}$ and F-Gasses. Thus, some former Communist EU members ( such as Bulgaria, Croatia, Estonia, Hungary, Latvia, Lithuania, Poland, and Romania) will act as pollution haven when trading more with Canada simply because they are poorer than Canada, and therefore, may have/adopt lax environmental rules and regulations (or simply a poor execution of the environmental rules and regulations). In other words, the implementation of CETA may help increase per capita emissions of $\mathrm{N}_{2} \mathrm{O}$ and F-Gasses in these former EU members because pollution would shift from Canada towards these EU members. The inverse would happen in Canada.

In addition to FEH, PHH1 and PHH2 as measured in $M 1 \& M 2$, trade between Canada and a subset of EU members in the sample could be affected by geographical, cultural, or political reasons. Therefore, per capita emissions of air pollutants could be affected more (or less) in this subset of CETA members. In order to emphasize these effects, the study employs $M 3$, where in addition to all variables included in $M 2$, it also employs three 
additional dummy variables.

In particular, the study applies the cross-product of trade with a dummy that is 1 if the official language is English and/or French, and 0 otherwise. This is denoted by EnglishFrench $=1 \times$ Trade and its slopes are reported in the $16^{\text {th }}$ row of the Tables 4-7, respectively. Since Canada uses both English and French as its official languages, it is expected to trade more with EU members that use either English or French as their official language as compared to other EU members that use neither English nor French as their official language. In the sample, there are $6 \mathrm{EU}$ members that use either English or French as one of their official languages. In the sample, about $47 \%$ of all of the volume of trade between the EU and Canada comes from trade between Canada and these $6 \mathrm{EU}$ members. The results report statistically significant evidence suggesting that a higher trade intensity between Canada and the EU members that use either English or French as their official language may help on average, reduce (increase) per capita emissions of $\mathrm{CO}_{2}$ and $\mathrm{CH}_{4}, \mathrm{CN}_{2} \mathrm{O}$ and $H F C s / P F C s / S_{6}$ ), respectively. This result for $\mathrm{CO}_{2}, \mathrm{CH}_{4}$, and F-Gasses could be interpreted simply with the role of trade. Since, there is more trade between Canada and the EU members that use one of Canada's official languages, we would see a further decrease (increase) of emissions per capita of $\mathrm{CO}_{2}$ and $\mathrm{CH}_{4}$ (F-Gasses) in these EU members as compared to those EU members that use neither English nor French as their official language.

Furthermore, the study employs the cross-product of trade with a dummy that is 1 if a CETA member has geographically access to the Sea or the Atlantic Ocean, and 0 otherwise. This is denoted by Sea $x$ Trade and its coefficients are reported in the $17^{\text {th }}$ row of Tables 4-7, respectively. The argument here is analogous to the previous paragraph, and therefore, it is expected for Canada to trade more with the EU members that have sea access relative to the landlocked EU members. In the sample, $96 \%$ of the overall volume of trade between Canada and the EU originates from trade between Canada and EU members that have access to the sea (there are only 5 landlocked EU members). The results indicate statistically significant evidence, irrespective of the empirical specification used in the study, implying that a higher trade insensitive between Canada and the EU members with sea access increases per capita emissions of $\mathrm{CO}_{2}$ and F-Gasses as compared to the impact of trade between Canada and landlocked EU members on these 2 pollutants. One may suggest that the later result could be associated with the fact that all landlocked EU members may be using intensively the ports of EU members that have sea access when trading with Canada. Therefore, the air pollution could increase in the EU members with sea access simply because of more trade between landlocked EU members and Canada.

Moreover, the study uses the cross-product of trade with a dummy that is 1 at the time when an EU member has adopted Euro as its official currency, and 0 otherwise. This is 
denoted by Euro $x$ Trade and its estimators are reported in the $18^{\text {th }}$ row of Tables 4-7, respectively. Analogously, the above two paragraphs, Canada is expected to trade more with EU members that have adopted Euro as their official currency relative to the EU members that use their own national official currency, due to lower costs from exchange rates transactions. In the sample, the volume of trade between Canada and the EU members that have adopted Euro as their official language consists of about $40 \%$ of the total volume of trade between Canada and the EU. One would theoretically expect a negative coefficient of the Euro dummy for $\mathrm{CO}_{2}, \mathrm{CH}_{4}$, and $\mathrm{N}_{2} \mathrm{O}$ following the main results of the paper (a negative relationship between the trade intensity variable and per capita emissions of each of these 3 pollutants). However, in a counter-intuitive way, the results report statistically significant evidence suggesting that per capita emissions of $\mathrm{CO}_{2}$ and $\mathrm{CH}_{4}$ increase in Eurozone countries due to the implementation of CETA as compared to non-Eurozone EU members.

The rest of this section previews the results in terms of the control variables used in the three models. First, in order to empirically validate the existence of the Environmental Kuznets Curve (EKC), the paper uses the coefficients of income per capita and its square value, denoted by $I$ and $I^{2}$, which are presented in rows $6^{\text {th }}$ and $7^{\text {th }}$ of Tables 4-7, respectively. The results yield statistically significant evidence that suggests the existence of a positive and monotonic relationship between per capita emissions of each of the four air pollutants and per capita income, respectively. This is inconsistent with the environmental Kuznets Curve (EKC) argument that suggests an inverted U-shaped relationship between air pollution and per capita income. ${ }^{8}$

Second, Tables 4-7 report the direct composition effect of growth captured by the capital-labor ratio and its squared value to measure its diminishing returns. These are denoted by $K L$ and $(K L)^{2}$, and are presented in rows $8^{\text {th }}$ and $9^{\text {th }}$, respectively. Third, Tables 4-7 show the general composition effect of growth measured by the cross-product of income per capita and capital to labor ratio. The later variable is denoted by $K L x I$ and is presented in rows $10^{\text {th }}$ row. The results show strong statistically significant evidence, regardless of the model or the empirical methodology used in the paper, in support of an U-shaped relationship between the direct composition effect of growth and per capita

\footnotetext{
${ }^{8}$ These results are consistent with Qirjo et al. (2019) who show the existence of a positive relationship between per capita income and per capita emissions of GHGs for CETA members. It also consistent with Pascalau and Qirjo (2017b), who show the same type of relationship between per capita income and per capita emissions of $\mathrm{N}_{2} \mathrm{O}$, using data during 1989-2013 time period for the possible TTIP members. On the other hand, the results of the current study are opposite to those reported in Pascalau and Qirjo (2017b) for $\mathrm{CO}_{2}, \mathrm{CH}_{4}$, and $H F C s / P F C s / S_{6}$, respectively. Pascalau and Qirjo (2017b) show robust and statistically significant evidence suggesting the presence of the EKC for each of the later three air pollutants, irrespective of the model or empirical specification employed in the paper.
} 
emissions of each of the 4 air pollutants, respectively. They also indicate strong and statistically significant evidence, regardless of the model or the empirical technique used in the study, suggesting a negative relationship between general composition effect of growth and per capita emissions of each of the four air pollutants.

Fourth, Tables 4-7 report a land per capita variable, denoted by $L P C$, in the $14^{\text {th }}$ row, respectively. In the following row, they also show its squared value denoted by $(L P C)^{2}$, in order to capture its diminishing returns. The latter two control variables are present in $M 2$ \& $M 3$, but are absent in $M 1$.The results indicate mainly statistically significant evidence suggesting a positive (negative) relationship of land per capita and emissions per capita of $\mathrm{CH}_{4}$ and $\mathrm{F}$-Gasses $\left(\mathrm{N}_{2} \mathrm{O}\right)$, respectively. This means that the more sparsely populated is a typical CETA member, the higher would be emissions per capita of $\mathrm{CH}_{4}$ and F-Gasses.

Fifth, Tables 4-7 present the impact of inward FDI as a portion of GDP on air pollution in the $13^{\text {th }}$ row. This is denoted by FDI/GDP and it is present in M2 \& M3 but it is absent in $M 1$. There is positive and mainly statistically significant evidence implying that CETA members with higher inward FDI to GDP ratio tend to also have higher per capita emissions of $\mathrm{CH}_{4}$ and $\mathrm{N}_{2} \mathrm{O}$, respectively. This result empirically validates the theory that suggests that multinational corporations may chose to transfer their pollution-intensive activities in foreign countries in order to take advantage of lower costs due to the existence of lax environmental rules and regulations in foreign lands as compared to higher costs associated to stringent environmental rules and regulations in their native countries.

\section{Conclusion}

This study empirically investigates the impact that a higher trade intensity between each $\mathrm{EU}$ member and Canada could have on each of the following air pollutants: $\mathrm{CO}_{2}, \mathrm{CH}_{4}$, $\mathrm{N}_{2} \mathrm{O}$, and $\mathrm{HFCs} / \mathrm{PFCs} / \mathrm{SF}_{6}$. The paper uses a panel dataset for Canada and $28 \mathrm{EU}$ members during the 1990-2016 time period. The study finds robust and statistically significant evidence suggesting a negative relationship between the trade intensity variable and per capita emissions of $\mathrm{CO}_{2}, \mathrm{CH}_{4}$, and $\mathrm{N}_{2} \mathrm{O}$, respectively. In particular, there is robust and statistically significant evidence suggesting that one percent increase of a percentage point of the trade intensity variable (proxied by the ratio of the bilateral volume of trade between Canada and a typical EU member to GDP) may help reduce per capita emissions of $\mathrm{CO}_{2}, \mathrm{CH}_{4}$, and $\mathrm{N}_{2} \mathrm{O}$ by about .48 percent, .65 percent, and 1.2 percent, respectively. Thus, the presence of CETA may help reduce more per capita emissions of $\mathrm{N}_{2} \mathrm{O}$ than $\mathrm{CH}_{4}$, than $\mathrm{CO}_{2}$. On the other hand, there is some limited empirical evidence that suggests that 
the implementation of CETA may help increase per capita emissions of $H F C s / P F C s / S F_{6}$. In particular, there is statistically significant evidence implying that one percent increase of a percentage point of the trade intensity variable between Canada and the EU may help increase per capita emissions of $H F C s / P F C s / S F_{6}$ by about 1.95 percent only under $M 2$ when employing the fixed effects allowing for cross-sectional robust standard errors methodology. However, the latter relationship is statistically insignificant under every other model or empirical techniques used in the study.

The above results stand due to the combinations of FEH, PHH2, and PHH1 channels as a consequence of more trade between Canada and the EU. More specifically, in the case of $\mathrm{CO}_{2}, \mathrm{FEH}$ and $\mathrm{PHH} 2$ dominate $\mathrm{PHH} 1$ for a typical EU member. Note that an average EU member is labor-abundant, poor and very densely populated as compared to Canada. In the latter trade partner, there is no statistically significant evidence suggesting a relationship between the trade intensity variable and per capita emissions of $\mathrm{CO}_{2}$. In other words, in the case of Canada, that is capital-abundant, rich and very sparsely populated as compared to a typical EU member, PHH1 cancels out FEH and PHH2. Thus, there is no shift of $\mathrm{CO}_{2}$ per capita from the EU towards Canada, despite the fact that there would be a decrease of emissions per capita of $\mathrm{CO}_{2}$ for an average EU member due to more trade between these two regions.

In the case of $\mathrm{CH}_{4}$, there is empirical evidence implying that $\mathrm{FEH}$ and $\mathrm{PHH} 2$ dominate PHH1 not only for a typical EU member, but also for Canada. Put it differently, there is a movement of $\mathrm{CH}_{4}$ emissions per capita from the EU towards Canada, as a consequence of more trade between these two regions. Thus, the implementation of CETA may force Canada to act as pollution haven for $\mathrm{CH}_{4}$ mainly due to being very sparsely populated as compared to each EU member (consistent to $\mathrm{PHH} 2$ channel).

Focusing on $\mathrm{N}_{2} \mathrm{O}$, there is empirical evidence implying that $\mathrm{FEH}$ and $\mathrm{PHH} 2$ dominate PHH1 for a typical EU member, but PHH1 dominates FEH and PHH2 in Canada. In other words, the implementation of CETA may help reduce per capita emissions of $\mathrm{N}_{2} \mathrm{O}$ not only in a typical EU member, but also in Canada. The trade elasticities reported in Table 10 suggest that there is a movement of $\mathrm{N}_{2} \mathrm{O}$ emissions per capita from Canada to 8 former Communist EU members due to more trade between Canada and the EU. Put it differently, the implementation of CETA may force these 8 former Communist EU members to act as pollution havens for $\mathrm{N}_{2} \mathrm{O}$ due to being much poorer than Canada (consistent to $\mathrm{PHH1}$ channel).

In the case of $H F C s / P F C s / S F_{6}$, there is limited empirical evidence (only under $M 2$ when employing the fixed effects with cross-sectional robust standard errors technique) implying that PHH1 dominates FEH and PHH2 not only for an average EU member, but also for 
Canada. In other words, there is a movement of $H F C s / P F C s / S F_{6}$ emissions per capita from Canada towards a typical EU member, as a consequence of more trade between these two regions. Thus, the implementation of CETA may force a typical EU member to act as pollution haven for $H F C s / P F C s / S F_{6}$ due to being poorer than Canada (consistent to PHH1 channel). However, there is no statistically significant evidence validating the latter argument for $H F C s / P F C s / S_{6}$ under most of the models and empirical strategies used in this paper. Consequently, on average, PHH1 cancels out FEH and PHH2 for an average EU member due to more trade with Canada.

This study provides statistically significant evidence in support of $\mathrm{PHH} 1$ and $\mathrm{PHH} 2$ for some pollutant. In particular, the trade elasticity of emissions per capita of $\mathrm{CH}_{4}$ coefficients reported in Table 9, provide unambiguous empirical evidence suggesting that Canada may act as pollution haven when increasing its trade volumes as a percentage of GDP with the EU because Canada is extremely sparsely populated as compared to each EU member. Thus, following PHH2 argument, originated from Frankel and Rose (2005), Canada may adopt lax environmental rules and regulations, while the EU may adopt stringent environmental rules and regulations (and/or more effective executions of these rules) that lead to a shift of emissions per capita of $\mathrm{CH}_{4}$ from the EU towards Canada due to the implementation of CETA. On the other hand, the trade elasticity of emissions per capita of $\mathrm{N}_{2} \mathrm{O}$ coefficients reported in Table 10, provide unambiguous empirical evidence suggesting that 8 former Communist EU members may act as pollution havens when increasing their trade intensity variable with Canada because these $8 \mathrm{EU}$ members are much poorer than Canada. Thus, following PHH1 argument these 8 former Communist EU members could adopt lax environmental rules and regulations that leads to a movement of emissions per capita of $\mathrm{N}_{2} \mathrm{O}$ from Canada towards these $9 \mathrm{EU}$ members as a consequence of CETA. Analogously to $\mathrm{N}_{2} \mathrm{O}$, the trade elasticity of emissions per capita of $H F C s / P F C s / S F_{6}$ coefficients reported in Table 11 provide empirical evidence in support of $P H H 1$ for $H F C s / P F C s / S F_{6}$. More specifically, the trade elasticities of Table 11 suggest that 8 former Communist EU members together with Malta may act as pollution haven due to trading more with Canada mainly because they are much poorer than Canada. Thus, there would be a shift of emissions per capita of $H F C s / P F C s / S F_{6}$ from Canada to these $9 \mathrm{EU}$ members. 


\section{References}

Antweiler, W., B. R. Copeland, and M. S. Taylor (2001, September). Is free trade good for the environment? American Economic Review 91(4), 877-908.

Cole, M. A. and R. J. Elliott (2003, November). Determining the trade-environment composition effect: The role of capital, labor and environmental regulations. Journal of Environmental Economics and Management 46(3), 363-383.

Cole, M. A. and P. G. Fredriksson (2009, February). Institutionalized pollution havens. Ecological Economics 68, 1239-1256.

Davis, S. J. and K. Caldeira (2010, March). Consumption-based accounting of CO2 emissions. Proceedings of the National Academy of Sciences of the United States of America 107(12), 5687-5692.

Frankel, J. A. and A. K. Rose (2005, February). Is trade good or bad for the environment? Sorting out the causality. Review of Economics and Statistics 87(1), 85-91.

Jaffe, A. B., S. R. Peterson, P. R. Portney, and R. N. Stavins (1995, March). Environmental regulation and the competitiveness of US manufacturing: What does the evidence tell us? Journal of Economic Literature 33(1), 132-163.

Levinson, A. and M. S. Taylor (2008, February). Unmasking the pollution haven effect. International Economic Review 49(1), 223-254.

Pascalau, R. and D. Qirjo (2017a). The role of TTIP on the environment. MPRA Working Paper, No. 79652.

Pascalau, R. and D. Qirjo (2017b). TTIP and the environmental Kuznets curve. MPRA Working Paper, No. 80192.

Qirjo, D. and R. Christopherson (2016). Will TAFTA Be Good or Bad for the Environment?, pp. 179-206. In Vikash Ramiah and Greg N. Gregoriou (ed): Handbook of Environmental and Sustainable Finance. Waltham, MA, Academic Press, Elsevier.

Qirjo, D. and R. Pascalau (2019a). The role of TTIP on other than CO2 air pollutants. MPRA Working Paper, No. 95633.

Qirjo, D. and R. Pascalau (2019b, April). The role of TTIP on the environment. Southern Economic Journal 85(4), 1262-1285. 
Qirjo, D., R. Pascalau, and D. Krichevkiy (2019). The role of CETA on air pollution. MPRA Working Paper, No. 95608.

UNFCCC (2019). United Nations Framework Convention on Climate Change Dataset. Available online at: https://unfccc.int. 


\section{Tables and Figures}

Table 2: Summary Statistics and Unit Root Tests

\begin{tabular}{|c|c|c|c|c|c|c|c|}
\hline Variable & Dimension & $\mathrm{N}$ & Mean & SD & Min & Max & Unit Root Tests \\
\hline $\mathrm{CO}_{2}$ & tons/capita & 783 & 13.60 & 25.43 & 2.99 & 184.43 & $-3.834 * * *+$ \\
\hline $\mathrm{N}_{2} \mathrm{O}$ & tons/capita & 783 & .956 & 1.50 & .09 & 10.19 & $-1.959 * *+$ \\
\hline $\mathrm{HFC} / \mathrm{PFC} / \mathrm{SF} 6$ & tons/capita & 783 & .16 & .13 & $2.32 \mathrm{e}-06$ & .89 & $-22.153 * * *+$ \\
\hline $\mathrm{CH}_{4}$ & tons/capita & 783 & 1.24 & .70 & .29 & 4.23 & $-1.313 *+$ \\
\hline Trade & $(\mathrm{X}+\mathrm{M}) / \mathrm{GDP}$ & 783 & $0.056 \%$ & $0.095 \%$ & $0.003 \%$ & $0.74 \%$ & $-6.857 * * * *$ \\
\hline Rel. K/L & $\mathrm{CAN}=1$ & 783 & 0.856 & 0.365 & 0.041 & 1.655 & $-5.774 *$ *末 \\
\hline Rel. I & $\mathrm{CAN}=1$ & 696 & 0.725 & 0.502 & 0.029 & 2.519 & $-2.745 * * *+$ \\
\hline Rel. LPC & $\mathrm{CAN}=1$ & 783 & 0.077 & 0.179 & 0.002 & 1 & N.A. \\
\hline I & 2011 USD & 696 & $27,894.18$ & $19,931.42$ & 949.97 & $117,633.5$ & $-2.313^{* *} \ddagger$ \\
\hline $\mathrm{K} / \mathrm{L}$ & 2011 USD & 783 & $248,425.3$ & 133,666 & $88,99.91$ & $690,601.9$ & $-1.400 * \ddagger$ \\
\hline FDI/GDP & $\%$ & 783 & 12.53 & 47.86 & -75.31 & 731.93 & $-6.909 * * *+$ \\
\hline LPC & Sq.Km/capita & 783 & 0.024 & 0.056 & 0.001 & 0.359 & $-2.478 * * *+$ \\
\hline
\end{tabular}

$* * *, * *$, and * denote significance at the $1 \%, 5 \%$, and $10 \%$ significance level, respectively. For all series, we use the $Z$-t-tilde-bar statistic of the Im-Pesaran-Shin unit-root test where the AR parameter is panel specific. The null states that all panels contain unit roots, while the alternative states that some panels are stationary. $*, \dagger, \ddagger$ means that the unit root test controls for (i) a trend only, (ii) trend and a squared trend term and (iii) trend, a squared trend, and a cubic trend term, respectively. Relative Land per Capita is stationary around a constant. 
Table 3: Relative (to Canada) Measures of Income, Capital/Labor and Land per Capita ratios

\begin{tabular}{l|c|c|c|} 
Country & Relative Income & Relative K/L ratio & Relative LPC ratio \\
\hline Austria & 1.117367 & 1.127084 & 0.032709 \\
Belgium & 1.045962 & 1.285901 & 0.009241 \\
Bulgaria & 0.101232 & 0.146827 & 0.045332 \\
Canada & 1 & 1 & 1 \\
Croatia & 0.247387 & 0.585975 & 0.04072 \\
Cyprus & 0.640459 & 1.136682 & 0.030083 \\
Czechia & 0.337635 & 1.002536 & 0.024289 \\
Denmark & 1.362923 & 1.046758 & 0.0254 \\
Estonia & 0.240707 & 0.483427 & 0.104469 \\
Finland & 1.086206 & 1.090806 & 0.205616 \\
France & 1.03528 & 1.032433 & 0.032846 \\
Germany & 1.081756 & 1.021696 & 0.013947 \\
Greece & 0.560493 & 1.186642 & 0.038921 \\
Hungary & 0.250218 & 0.570419 & 0.029318 \\
Ireland & 1.106298 & 0.987077 & 0.055093 \\
Italy & 0.884257 & 1.326103 & 0.016532 \\
Latvia & 0.188636 & 0.628461 & 0.091297 \\
Lithuania & 0.199943 & 0.388242 & 0.062963 \\
Luxembourg & 2.193493 & 1.377379 & 0.017903 \\
Malta & 0.441521 & 0.562086 & 0.002523 \\
Netherlands & 1.159178 & 0.967618 & 0.008222 \\
Poland & 0.211064 & 0.321403 & 0.026071 \\
Portugal & 0.496686 & 0.944284 & 0.02846 \\
Romania & 0.123457 & 0.285539 & 0.035586 \\
Slovakia & 0.255806 & 0.586686 & 0.029074 \\
Slovenia & 0.493314 & 0.846416 & 0.032077 \\
Spain & 0.682424 & 1.013103 & 0.037631 \\
Sweden & 1.259957 & 1.053778 & 0.157782 \\
UK & 1.062318 & 0.843649 & 0.01283 \\
\hline & & & \\
\hline
\end{tabular}


Table 4: Dependent Variable CO2 - Base Results

\begin{tabular}{|c|c|c|c|c|c|c|c|c|c|c|c|c|}
\hline Estimation Method & \multicolumn{3}{|c|}{ Fixed Effects } & \multicolumn{3}{|c|}{ Random Effects } & \multicolumn{3}{|c|}{ Cross Section Dependence } & \multicolumn{3}{|c|}{ Serial Correlation Effects } \\
\hline Specification & M1 & M2 & M3 & M1 & M2 & M3 & M1 & M2 & M3 & M1 & M2 & M3 \\
\hline Column & (1) & (2) & (3) & (4) & (5) & (6) & (7) & (8) & (9) & (10) & (11) & (12) \\
\hline Trade & $-196.357^{* k * k}$ & $-184.919^{k * k}$ & $-270.687^{* * k}$ & $-197.996^{* k *}$ & $-199.685^{* k *}$ & $-258.011^{k * k}$ & $-196.357^{* * *}$ & $-184.919^{* * k}$ & $-270.687^{\text {** }}$ & $-292.369^{* \cdots * k}$ & $-272.860^{* * * k}$ & $-408.887^{* * k}$ \\
\hline Trade $\times$ RKL & 304.584 & 235.641 & 135.304 & 297.697 & 246.292 & 141.034 & 304.584 & 235.641 & 135.304 & $630.897^{*}$ & 520.167 & 510.407 \\
\hline Trade $\times(R K L)^{2}$ & $-167.913^{*}$ & $-147.647^{*}$ & -133.466 & $-164.703^{*}$ & $-154.606^{*}$ & -137.998 & $-167.913^{*}$ & -147.647 & -133.466 & -186.486 & -148.871 & -158.918 \\
\hline Trade $\times$ RI & 134.881 & 204.270 & 170.893 & 147.104 & 226.598 & 209.747 & 134.881 & 204.270 & 170.893 & -163.126 & -72.947 & -88.065 \\
\hline Trade $\times(R I)^{2}$ & -85.319 & $-131.581^{* *}$ & -88.758 & -89.228 & $-138.505^{* *}$ & -104.321 & -85.319 & -131.581 & -88.758 & 44.015 & -1.543 & 28.769 \\
\hline I & $.946^{* * *}$ & .150 & .203 & $.926^{* * *}$ & .334 & .371 & $.946^{* * *}$ & .150 & .203 & $1.268^{* * *}$ & $.569^{*}$ & $.587 *$ \\
\hline$I^{2}$ & $.112^{* * *}$ & $.124^{* * *}$ & $.105^{* * * *}$ & $.113^{* * *}$ & $.121^{* * *}$ & $.103^{* * * *}$ & $.112^{* * *}$ & $.124^{* * *}$ & $.105^{* * *}$ & $.111^{* * * *}$ & $.120^{* * * *}$ & $.110^{* * * *}$ \\
\hline $\mathrm{KL}$ & $-1.115^{* * *}$ & $-.850^{* * *}$ & $-.855^{* * *}$ & $-1.119^{* * *}$ & $-.928^{* * *}$ & $-.921^{* * *}$ & $-1.115^{* * *}$ & $-.850^{* *}$ & $-.855^{* *}$ & -.328 & -.061 & -.092 \\
\hline$(K L)^{2}$ & $.143^{* * *}$ & $.114^{* * *}$ & $.106^{* * *}$ & $.142^{* * *}$ & $.121^{* * *}$ & $.113^{* * *}$ & $.143^{* * *}$ & $.114^{* * * *}$ & $.106^{* * *}$ & $.108^{* * * k}$ & $.081^{* *}$ & $.077^{* * *}$ \\
\hline $\mathrm{KL} \times \mathrm{I}$ & $-.245^{* * *}$ & $-.198^{* * *}$ & $-.174^{* * * *}$ & $-.244^{* * *}$ & $-.208^{* * *}$ & $-.185^{* * *}$ & $-.245^{* * * *}$ & $-.198^{* * * *}$ & $-.174^{* * * *}$ & $-.267^{* * * *}$ & $-.224^{* * * *}$ & $-.210^{* * * *}$ \\
\hline Trade $\times$ RLPC & & $837.442^{* * *}$ & 29.742 & & $997.882^{* *}$ & 135.099 & & $837.442^{*}$ & 29.742 & & 790.889 & -453.126 \\
\hline Trade $\times(R L P C)^{2}$ & & $-773.346^{*}$ & 125.559 & & $-943.137^{* * *}$ & 10.924 & & $-773.346^{*}$ & 125.559 & & -740.390 & 540.370 \\
\hline FDI/GDP & & .010 & .008 & & .009 & .007 & & .010 & .008 & & .015 & .014 \\
\hline LPC & & .069 & -.214 & & -.066 & -.285 & & .069 & -.214 & & .312 & .059 \\
\hline$(L P C)^{2}$ & & -.045 & $-.086^{* * * *}$ & & -.043 & $-.076^{* * *}$ & & -.045 & $-.086^{* * *}$ & & -.016 & -.053 \\
\hline English $\times$ Trade & & & $-133.580^{* * *}$ & & & $-137.329^{* * *}$ & & & $-133.580^{* *}$ & & & $-148.747^{* * *}$ \\
\hline Sea $\times$ Trade & & & $197.867^{* * *}$ & & & $173.870^{* * *}$ & & & $197.867^{\text {** }}$ & & & 246.517 \\
\hline Euro $\times$ Trade & & & $87.999^{* * * *}$ & & & $83.670^{* * * *}$ & & & $87.999^{* * * *}$ & & & $53.087^{* * *}$ \\
\hline Constant & $3.828^{* * * *}$ & $7.145^{* * * *}$ & $6.528^{* * *}$ & $3.912^{* k *}$ & $6.028^{* * * *}$ & $5.544^{* k * k}$ & $3.680^{* * * *}$ & $6.967 * * *$ & $6.351^{* * *}$ & -1.103 & 2.324 & 2.031 \\
\hline $\mathrm{N}$ & 696.000 & 696.000 & 696.000 & 696.000 & 696.000 & 696.000 & 696.000 & 696.000 & 696.000 & 696.000 & 696.000 & 696.000 \\
\hline R2 & .547 & .571 & .587 & & & & .986 & .987 & .987 & & & \\
\hline R2 adj. & .503 & .526 & .542 & & & & & & & & & \\
\hline bic & -1324.427 & -1330.096 & -1337.042 & & & & & & & & & \\
\hline
\end{tabular}

****, ***, and * denote significance at the 1\%, 5\%, and 10\% significance level, respectively. M1, M2, and M3 correspond to the three models outlined in equations (1), (2), and (3), respectively. Cross Section Dependence represents a fixed effects regression where we allow for cross-section dependence among countries. Serial correlation effects denote a fixed effects regression setting with Driscoll-Kraay standard errors where we allow for an MA(2) component to account for the serial correlation effects in the residuals. GDP per capita is denoted by I and it is calculated as the three-year moving average of the lagged value of GDP per capita, $I_{i t}=0.6 * I_{i t-1}+0.3 * I_{i t-2}+0.1 * I_{i t-3}$. All the other variables are in their contemporaneous values. Trade is the sum of exports and imports (between trading partners, the US on one side and each EU member on the other side) over GDP. All relative variables denoted by R in front of them are constructed relative to the US. KL denotes the capital to labor ratio that also measures the direct composition of growth. FDI/K is the ratio of the stock of inward FDI to the physical stock of capital. It is also used as a proxy to measure PHH. LPC denotes the land area per capita. KL $\times$ I denotes the general composition of growth. Trade $\times$ RKL and Trade $\times(R K L)^{2}$ measure FEH. Trade $\times$ RI and Trade $\times(R I)^{2}$ measure PHH1. Trade $\times$ RLPC and Trade $\times(R L P C)^{2}$ measure PHH2. English $\times$ Trade is a dummy variable. If a country uses English as one of their official languages, we put the value of our Trade variable otherwise we put zero. Sea $\times$ Trade is a dummy variable. If a country has access to the sea or the ocean, we put the value of our Trade variable otherwise we put zero. Euro $\times$ Trade is a dummy variable. If the country uses Euro as its national currency, we put the value of our Trade variable otherwise we put zero.

Table 5: Dependent Variable (CH4) - Base Results

\begin{tabular}{|c|c|c|c|c|c|c|c|c|c|c|c|c|}
\hline Estimation Method & \multicolumn{3}{|c|}{ Fixed Effects } & \multicolumn{3}{|c|}{ Random Effects } & \multicolumn{3}{|c|}{ Cross Section Dependence } & \multicolumn{3}{|c|}{ Serial Correlation Effects } \\
\hline Specification & M1 & M2 & M3 & M1 & M2 & M3 & M1 & M2 & M3 & M1 & M2 & $\mathrm{M} 3$ \\
\hline Column & (1) & (2) & (3) & (4) & (5) & (6) & (7) & (8) & (9) & (10) & (11) & (12) \\
\hline Trade & -65.997 & 96.471 & $237.731^{* * *}$ & -87.307 & 68.577 & $189.862 *$ & -65.997 & 96.471 & $237.731^{* *}$ & -150.531 & 2.952 & 83.907 \\
\hline Trade $\times$ RKL & 155.478 & -140.906 & -239.305 & 173.355 & -66.271 & -156.036 & 155.478 & -140.906 & -239.305 & 450.561 & 150.622 & 78.394 \\
\hline Trade $\times(R K L)^{2}$ & $-268.574 * * *$ & $-139.423^{*}$ & -116.020 & $-271.119 * * * *$ & $-167.979 * *$ & $-147.086^{*}$ & $-268.574 * * *$ & -139.423 & -116.020 & $-333.368^{* * *}$ & $-202.995 *$ & $-187.713^{*}$ \\
\hline Trade $\times$ RI & $227.565^{*}$ & 183.755 & $253.280 *$ & $255.698^{*}$ & 174.681 & $241.018 *$ & $227.565^{*}$ & 183.755 & $253.280 *$ & -2.510 & -27.062 & 26.425 \\
\hline Trade $\times(R I)^{2}$ & -71.162 & -51.210 & -79.305 & -76.703 & -49.212 & -73.519 & -71.162 & -51.210 & -79.305 & 44.740 & 60.681 & 43.831 \\
\hline I & $1.871 * * *$ & $1.467 * * *$ & $1.451 * * *$ & $1.954 * * *$ & $1.691 * * *$ & $1.686 * * *$ & $1.871^{* * *}$ & $1.467 * * *$ & $1.451^{* * *}$ & $2.506 * * *$ & $2.192 * * *$ & $2.176^{* * * *}$ \\
\hline$I^{2}$ & $.098^{* * * *}$ & $.101^{* * *}$ & $.096^{* * * *}$ & $.096^{* * * *}$ & $.096^{* * * *}$ & $.091^{* * * *}$ & $.098^{* * *}$ & $.101 * * *$ & $.096^{* * * *}$ & $.074 * * *$ & $.076^{* * * *}$ & $.071^{* * * *}$ \\
\hline KL & $-3.262 * * * *$ & $-3.083^{* * * *}$ & $-3.057 * * *$ & $-3.268 * * *$ & $-3.173^{* * *}$ & $-3.148 * * *$ & $-3.262^{* * * *}$ & $-3.083^{* * *}$ & $-3.057 * * *$ & $-2.742^{* * * *}$ & $-2.583^{* * * *}$ & $-2.563^{* * *}$ \\
\hline$(K L)^{2}$ & $.262 * * *$ & $.244 * * *$ & $.241 * * *$ & $.264 * * *$ & $.252^{* * *}$ & $.249 * * *$ & $.262^{* * * *}$ & $.244 * * *$ & $.241 * * *$ & $.240 * * *$ & $.225^{* * * *}$ & $.221 * * *$ \\
\hline $\mathrm{KL} \times \mathrm{I}$ & $-.299 * * *$ & $-.269 * * *$ & $-.262 * * *$ & $-.303^{* * *}$ & $-.282 * * *$ & $-.274 * * *$ & $-.299 * * *$ & $-.269 * * *$ & $-.262^{* * * *}$ & $-.318 * * *$ & $-.295^{* * *}$ & $-.286^{* * * *}$ \\
\hline Trade $\times$ RLPC & & -606.264 & -959.276 & & -558.784 & $-1024.108 *$ & & $-606.264 *$ & $-959.276^{* * *}$ & & $-647.469 * *$ & $-1266.786^{\text {米菂 }}$ \\
\hline Trade $\times(R L P C)^{2}$ & & $776.790 * *$ & $1178.461^{*}$ & & $688.034 *$ & $1200.656^{* *}$ & & $776.790 * *$ & $1178.461^{* * *}$ & & $788.395^{* * *}$ & $1449.903^{* * * *}$ \\
\hline FDI/GDP & & $.052^{* * * *}$ & $.051^{* * *}$ & & $.052^{* * * *}$ & $.051^{* * *}$ & & $.052^{* * *}$ & $.051^{* * *}$ & & $.049 * * *$ & $.048^{* * *}$ \\
\hline LPC & & $.590 * *$ & $.539 *$ & & .145 & .103 & & $.590 * * *$ & $.539^{* * *}$ & & $.832^{* * * *}$ & $.741^{* *}$ \\
\hline$(L P C)^{2}$ & & .034 & .029 & & -.005 & -.009 & & .034 & .029 & & $.064^{* * *}$ & $.054 *$ \\
\hline English $\times$ Trade & & & -67.546 & & & -76.916 & & & -67.546 & & & $-90.030 * *$ \\
\hline Sea $\times$ Trade & & & -84.771 & & & -58.629 & & & -84.771 & & & -10.510 \\
\hline Euro $\times$ Trade & & & $34.940 *$ & & & $34.649 *$ & & & 34.940 & & & 36.582 \\
\hline Constant & $9.002^{* * *}$ & $11.657^{* * * *}$ & $11.359 * * *$ & $8.766^{* * * *}$ & $10.046^{* * *}$ & $9.764^{* * *}$ & $8.722^{* * * *}$ & $11.459 * * *$ & $11.114^{* * *}$ & $4.425^{* * *}$ & $7.279 * * *$ & $6.984^{* * * 4}$ \\
\hline $\mathrm{N}$ & 696.000 & 696.000 & 696.000 & 696.000 & 696.000 & 696.000 & 696.000 & 696.000 & 696.000 & 696.000 & 696.000 & 696.000 \\
\hline R2 & .703 & .733 & .735 & & & & .974 & .976 & .977 & & & \\
\hline R2 adj. & .674 & .705 & .706 & & & & & & & & & \\
\hline BIC & -1415.335 & -1457.712 & -1443.661 & & & & & & & & & \\
\hline
\end{tabular}

$* * * * *$, and * denote significance at the $1 \%, 5 \%$, and 10\% significance level, respectively. M1, M2, and M3 correspond to the three models outlined in equations (1), (2), and (3), respectively. Cross Section Dependence represents a fixed effects regression where we allow for cross-section dependence among countries. Serial correlation effects denote a fixed effects regression setting with Driscoll-Kraay standard errors where we allow for an MA(2) component to account for the serial correlation effects in the residuals. GDP per capita is denoted by I and it is calculated as the three-year moving average of the lagged value of GDP per capita, $I_{i t}=0.6 * I_{i t-1}+0.3 * I_{i t-2}+0.1 * I_{i t-3}$. All the other variables are in their contemporaneous values. Trade is the sum of exports and imports (between trading partners, the US on one side and each EU member on the other side) over GDP. All relative variables denoted by R in front of them are constructed relative to the US. KL denotes the capital to labor ratio that also measures the direct composition of growth. FDI/K is the ratio of the stock of inward FDI to the physical stock of capital. It is also used as a proxy to measure PHH. LPC denotes the land area per capita. KL $\times$ I denotes the general composition of growth. Trade $\times$ RKL and Trade $\times(R K L)^{2}$ measure FEH. Trade $\times$ RI and Trade $\times(R I)^{2}$ measure PHH1. Trade $\times$ RLPC and Trade $\times(R L P C)^{2}$ measure PHH2. English $\times$ Trade is a dummy variable. If a country uses English as one of their official languages, we put the value of our Trade variable otherwise we put zero. Sea $\times$ Trade is a dummy variable. If a country has access to the sea or the ocean, we put the value of our Trade variable otherwise we put zero. Euro $\times$ Trade is a dummy variable. If the country uses Euro as its national currency, we put the value of our Trade variable otherwise we put zero. 
Table 6: Dependent Variable (N2O) - Base Results

\begin{tabular}{|c|c|c|c|c|c|c|c|c|c|c|c|c|}
\hline Estimation Method & \multicolumn{3}{|c|}{ Fixed Effects } & \multicolumn{3}{|c|}{ Random Effects } & \multicolumn{3}{|c|}{ Cross Section Dependence } & \multicolumn{3}{|c|}{ Serial Correlation Effects } \\
\hline Specification & M1 & M2 & M3 & M1 & $\mathrm{M} 2$ & M3 & M1 & M2 & M3 & M1 & M2 & M3 \\
\hline Column & (1) & (2) & (3) & (4) & (5) & (6) & (7) & (8) & (9) & (10) & (11) & (12) \\
\hline Trade & 13.798 & 26.767 & -107.632 & 4.861 & 14.138 & -101.860 & 13.798 & 26.767 & -107.632 & -16.960 & 1.467 & -181.743 \\
\hline Trade $\times$ RKL & 240.719 & 201.713 & 218.078 & 238.106 & 201.488 & 228.449 & 240.719 & 201.713 & 218.078 & 367.782 & 316.153 & 341.537 \\
\hline Trade $\times(R K L)^{2}$ & $-295.701 * * *$ & $-296.231^{* * * *}$ & $-290.608^{* * * *}$ & $-292.717^{* * * *}$ & $-297.361^{* * * *}$ & $-295.895 * \ldots *$ & $-295.701 * * *$ & $-296.231 \ldots * *$ & $-290.608^{* * *}$ & $-340.404 * *$ & $-334.209^{* *}$ & -332.836 \\
\hline Trade $\times$ RI & -153.429 & -94.684 & -217.633 & -128.678 & -68.178 & -175.913 & -153.429 & -94.684 & -217.633 & -269.695 & $-225.643 * *$ & $-357.495 * *$ \\
\hline Trade $\times(R I)^{2}$ & 36.027 & -25.199 & 26.387 & 27.604 & -33.303 & 9.679 & 36.027 & -25.199 & 26.387 & $130.010^{*}$ & $87.875^{* * *}$ & $148.789 * *$ \\
\hline I & $1.396^{* * * *}$ & .264 & .231 & $1.399 * * *$ & .444 & .418 & $1.396^{* * * *}$ & .264 & .231 & $2.045^{* * * *}$ & $1.141^{* * *}$ & $1.117^{* * *}$ \\
\hline$I^{2}$ & $.061^{* * *}$ & $.077 * * *$ & $.077^{* * * *}$ & $.062 \% * *$ & $.074 * * *$ & $.075^{* * *}$ & $.061^{* *}$ & $.077^{* * * *}$ & $.077^{* * * *}$ & .030 & .040 & .037 \\
\hline KL & $-1.378^{* * * *}$ & -1.057 **** & $-1.056^{* \ldots * *}$ & $-1.384^{* * * *}$ & $-1.123^{* * * *}$ & $-1.126^{* * * *}$ & $-1.378^{* * * *}$ & $-1.057^{* * * *}$ & $-1.056^{* \ldots *}$ & $-1.198 * *$ & $-.880^{* *}$ & $-.885 *$ \\
\hline$(K L)^{2}$ & $.139 \% * *$ & $.100 * * *$ & $.098^{* * * *}$ & $.139 * * *$ & .107 ** & $.106^{* * *}$ & $.139 \%$ & $.100 \%$ & $.098^{* * *}$ & $.131^{* * * *}$ & $.095^{* *}$ & $.093 *$ \\
\hline $\mathrm{KL} \times \mathrm{I}$ & $-.197 * * *$ & $-.128 * * *$ & $-.124 * * * *$ & $-.198 \% * *$ & $-.138^{* * * *}$ & $-.137 * * * *$ & $-.197 \% * *$ & $-.128 * * * *$ & $-.124 * * *$ & $-.208 * * *$ & $-.149 * * *$ & $-.144 * *$ \\
\hline Trade $\times$ RLPC & & $1290.611^{* * *}$ & $2398.395^{* \ldots * *}$ & & $1448.608^{* * * *}$ & $2475.487 * * * *$ & & $1290.611^{* * *}$ & $2398.395^{* * * *}$ & & 1127.392 & 2022.907* \\
\hline Trade $\times(R L P C)^{2}$ & & $-1155.896^{* * *}$ & -2264.772 & & $-1314.977^{* * *}$ & $-2352.411^{* * * *}$ & & $-1155.896 *$ & $-2264.772^{\ldots * *}$ & & -1000.358 & -1895.673 \\
\hline FDI/GDP & & $.016^{*}$ & $.017^{*}$ & & .015 & $.016^{*}$ & & $.016^{* * * *}$ & $.017^{* \ldots * *}$ & & $.018^{* * *}$ & $.019 * * *$ \\
\hline LPC & & -.434 & -.398 & & $-.507^{*}$ & -.480 & & $-.434 *$ & $-.398 *$ & & -.190 & -.204 \\
\hline$(L P C)^{2}$ & & $-.121^{* * *}$ & $-.121^{* * * *}$ & & $-.112^{* * *}$ & $-.112^{* * * *}$ & & $-.121 * * *$ & $-.121^{* \ldots *}$ & & $-.087^{* * * *}$ & $-.095 * \ldots *$ \\
\hline English $\times$ Trade & & & $126.509^{*}$ & & & $120.205^{*}$ & & & 126.509* & & & 101.726 \\
\hline Sea $\times$ Trade & & & 53.338 & & & 35.733 & & & 53.338 & & & 119.399 \\
\hline Euro $\times$ Trade & & & -9.880 & & & -14.703 & & & -9.880 & & & -2.969 \\
\hline Constant & -.028 & $3.717 * *$ & $4.080^{* * *}$ & -.010 & $2.709^{*}$ & $3.015^{* *}$ & -.483 & $3.154 *$ & $3.565^{* *}$ & $-2.979 *$ & .304 & .600 \\
\hline $\mathrm{N}$ & 696.000 & 696.000 & 696.000 & 696.000 & 696.000 & 696.000 & 696.000 & 696.000 & 696.000 & 696.000 & 696.000 & 696.000 \\
\hline R2 & .650 & .681 & .683 & & & & .980 & .982 & .982 & & & \\
\hline R2 adj. & .616 & .647 & .648 & & & & & & & & & \\
\hline BIC & -1024.184 & -1055.986 & -1040.971 & & & & & & & & & \\
\hline
\end{tabular}

******, and * denote significance at the $1 \%, 5 \%$, and $10 \%$ significance level, respectively. M1, M2, and M3 correspond to the three models outlined in equations (1), (2), and (3), respectively. Cross Section Dependence represents a fixed effects regression where we allow for cross-section dependence among countries. Serial correlation effects denote a fixed effects regression setting with Driscoll-Kraay standard errors where we allow
for an MA(2) component to account for the serial correlation effects in the residuals. GDP per capita is denoted by I and it is calculated as the three-year moving average of the lagged value of GDP per capita, $I_{i t}=$ for an MA(2) component to account for the serial correlation effects in the residuals. GDP per capita is denoted by I and it is calculated as the three-year moving average of the lagged value of GDP per capita, $I_{i t}=$
$0.6 * I_{i t-1}+0.3 * I_{i t-2}+0.1 * I_{i t-3}$. All the other variables are in their contemporaneous values. Trade is the sum of exports and imports (between trading partners, the US on one side and each EU member on the other side) $0.6 * I_{i t-1}+0.3 * I_{i t-2}+0.1 * I_{i t-3}$. All the other variables are in their contemporaneous values. Trade is the sum of exports and imports (between trading partners, the US on one side and each EU member on the other side)
over GDP. All relative variables denoted by R in front of them are constructed relative to the US. KL denotes the capital to labor ratio that also measures the direct composition of growth. FDI/K is the ratio of the stock of inward over GDP. All relative variables denoted by R in front of them are constructed relative to the US. KL denotes the capital to labor ratio that also measures the direct composition of growth. FDI/K is the ratio of the stock of inward
FDI to the physical stock of capital. It is also used as a proxy to measure PHH. LPC denotes the land area per capita. KL $\times$ I denotes the general composition of growth. Trade $\times$ RKL and Trade $\times(R K L)^{2}$ measure FEH. Trade $\times$ RI and Trade $\times(R I)^{2}$ measure PHH1. Trade $\times$ RLPC and Trade $\times(R L P C)^{2}$ measure PHH2. English $\times$ Trade is a dummy variable. If a country uses English as one of their official languages, we put the value of our Trade variable otherwise we put zero. Sea $\times$ Trade is a dummy variable. If a country has access to the sea or the ocean, we put the value of our Trade variable otherwise we put zero. Euro $\times$ Trade is a dummy variable. If the country uses Euro as its national currency, we put the value of our Trade variable otherwise we put zero.

\section{Table 7: Dependent Variable HFC/PFC/SF6 (F-Gasses) - Base Results}

\begin{tabular}{|c|c|c|c|c|c|c|c|c|c|c|c|c|}
\hline Estimation Method & \multicolumn{3}{|c|}{ Fixed Effects } & \multicolumn{3}{|c|}{ Random Effects } & \multicolumn{3}{|c|}{ Cross Section Dependence } & \multicolumn{3}{|c|}{ Serial Correlation Effects } \\
\hline Specification & M1 & M2 & M3 & M1 & M2 & M3 & M1 & M2 & M3 & M1 & M2 & M3 \\
\hline Column & (1) & (2) & (3) & (4) & (5) & (6) & (7) & (8) & (9) & (10) & (11) & (12) \\
\hline Trade & 674.797 & 439.328 & 571.245 & 173.973 & 147.790 & 217.505 & 674.797* & 439.328 & 571.245 & 423.036 & 170.603 & 275.627 \\
\hline Trade $\times$ RKL & -26.338 & -442.766 & -735.748 & 294.682 & 44.214 & -257.703 & -26.338 & -442.766 & -735.748 & 730.407 & 343.955 & 13.223 \\
\hline Trade $\times(R K L)^{2}$ & -408.186 & -264.263 & -142.939 & -540.468 & -493.796 & -411.765 & -408.186 & -264.263 & -142.939 & -607.161 & -488.919 & -347.919 \\
\hline Trade $\times$ RI & -1030.637 & -76.653 & -313.881 & 10.094 & 373.404 & 209.312 & -1030.637 & -76.653 & -313.881 & $-1437.755^{* *}$ & -452.070 & -722.460 \\
\hline Trade $\times(R I)^{2}$ & $640.771^{*}$ & 315.801 & 386.219 & 107.725 & -50.787 & 62.871 & $640.771 * *$ & 315.801 & 386.219 & $797.252^{* * * *}$ & 449.138 & 540.077 \\
\hline I & $12.050 * \div * \pi$ & $11.041^{* * *}$ & $10.574 \% * *$ & $13.363^{* * * *}$ & $13.128 * * * *$ & $12.921 \%$ & $12.050 \%$ & $11.041^{* * *}$ & $10.574 * * *$ & $12.589 \% * *$ & $11.699 * * *$ & $11.162 * * *$ \\
\hline$I^{2}$ & .106 & .118 & .104 & .036 & .014 & -.010 & $.106^{* * *}$ & $.118^{* * *}$ & $.104 *$ & .051 & .067 & .051 \\
\hline $\mathrm{KL}$ & $-18.975^{* \ldots *}$ & $-17.769^{* * * *}$ & $-17.267^{* * * *}$ & $-19.515^{* * *}$ & $-19.336^{* * *}$ & $-18.966 * * *$ & $-18.975 \ldots *$ & $-17.769 * * *$ & $-17.267^{* * * *}$ & $-17.452^{* \ldots * *}$ & $-16.544 \% * *$ & $-15.905^{* \ldots *}$ \\
\hline$(K L)^{2}$ & $1.178^{* * * *}$ & $1.105^{* * *}$ & $1.063^{* * *}$ & $1.204 * * *$ & $1.181^{* * * *}$ & $1.147 * * *$ & $1.178^{* \ldots *}$ & $1.105^{* * *}$ & $1.063^{* * *}$ & $1.090^{* * *}$ & $1.038^{* * * *}$ & $.986 \% *$ \\
\hline $\mathrm{KL} \times \mathrm{I}$ & $-1.051^{* * * *}$ & $-.992^{* * * *}$ & $-.933 * * *$ & $-1.064 * * *$ & $-1.016^{* * * *}$ & $-.963^{* \ldots * *}$ & $-1.051 * * *$ & $-.992 * * *$ & $-.933^{* \ldots *}$ & $-1.017^{* * * * *}$ & $-.976^{* * * *}$ & $-.906^{* * * *}$ \\
\hline Trade $\times$ RLPC & & $5459.331^{* *}$ & $11070.314^{* * * *}$ & & 3352.445 & 5161.864 & & $5459.331^{* * * *}$ & $11070.314^{* \ldots * * * *}$ & & 5248.979 ** & $11173.393^{* * * * *}$ \\
\hline Trade $\times(R L P C)^{2}$ & & $-5670.628^{* * *}$ & $-11121.414 * \ldots * *$ & & -3338.101 & -4907.874 & & $-5670.628 * \ldots * \pi$ & $-11121.414^{* * * * *}$ & & $-5500.251^{* *}$ & $-11231.087 \% * *$ \\
\hline FDI/GDP & & .074 & .075 & & .065 & .065 & & .074 & .075 & & .070 & .072 \\
\hline LPC & & $5.162^{* \ldots * \pi}$ & $5.420 * * *$ & & .375 & .455 & & $5.162^{* * *}$ & $5.420 \ldots$ & & $5.211 *$ & $5.438 * *$ \\
\hline$(L P C)^{2}$ & & $.564 * * *$ & $.594 * * *$ & & .049 & .060 & & $.564 \% * *$ & $.594^{* * *}$ & & $.582 \%$ & $.607^{*}$ \\
\hline English $\times$ Trade & & & 521.459 & & & 9.368 & & & $521.459 * *$ & & & $526.714^{*}$ \\
\hline Sea $x$ & & & -470.650 & & & -68.174 & & & $-470.650^{*}$ & & & $-446.423^{*}$ \\
\hline Euro $\times$ Trade & & & 40.118 & & & 189.711 & & & 40.118 & & & 63.536 \\
\hline Constant & $50.634^{* * * *}$ & $59.551 * * *$ & $59.139 * * *$ & $48.822 * * * *$ & $49.292 * * *$ & $48.057^{* * * *}$ & $50.612^{* * * *}$ & $60.173^{* * * *}$ & $59.764 * * *$ & $40.972 * *$ & $50.703^{* * *}$ & $49.804^{* * *}$ \\
\hline $\mathrm{N}$ & 661.000 & 661.000 & 661.000 & 661.000 & 661.000 & 661.000 & 661.000 & 661.000 & 661.000 & 661.000 & 661.000 & 661.000 \\
\hline R2 & .594 & .607 & .609 & & & & .781 & .788 & .790 & & & \\
\hline R2 adj. & .552 & .564 & .564 & & & & & & & & & \\
\hline BIC & 1062.499 & 1072.458 & 1088.178 & & & & & & & & & \\
\hline
\end{tabular}

******, and * denote significance at the 1\%,5\%, and 10\% significance level, respectively. M1, M2, and M3 correspond to the three models outlined in equations (1), (2), and (3), respectively. Cross Section Dependence represents a fixed effects regression where we allow for cross-section dependence among countries. Serial correlation effects denote a fixed effects regression setting with Driscoll-Kraay standard errors where we allow for an MA(2) component to account for the serial correlation effects in the residuals. GDP per capita is denoted by I and it is calculated as the three-year moving average of the lagged value of GDP per capita, $I_{i t}=0.6 * I_{i t-1}+0.3 * I_{i t-2}+0.1 * I_{i t-3}$. All the other variables are in their contemporaneous values. Trade is the sum of exports and imports (between trading partners, the US on one side and each EU member on the other side) over GDP. All relative variables denoted by $\mathrm{R}$ in front of them are constructed relative to the US. KL denotes the capital to labor ratio that also measures the direct composition of growth. FDI/K is the ratio of the stock of inward FDI to the physical stock of capital. It is also used as a proxy to measure PHH. LPC denotes the land area per capita. KL $\times$ I denotes the general composition of growth. Trade $\times$ RKL and Trade $\times(R K L)^{2}$ measure FEH. Trade $\times$ RI and Trade $\times(R I)^{2}$ measure PHH1. Trade $\times$ RLPC and Trade $\times(R L P C)^{2}$ measure PHH2. English $\times$ Trade is a dummy variable. If a country uses English as one of their official languages, we put the value of our Trade variable otherwise we put zero. Sea $\times$ Trade is a dummy variable. If a country has access to the se. 
Table 8: Trade Elasticity of CO2 Coefficients

\begin{tabular}{|c|c|c|c|c|c|c|c|c|c|}
\hline Estimation Method & $\begin{array}{r}\text { M1 (FE) } \\
\text { (1) }\end{array}$ & $\begin{array}{r}\text { M1 (RE) } \\
\text { ( } 2)\end{array}$ & $\begin{array}{r}\text { M1 (CSD) } \\
\text { ( } 3 \text { ) }\end{array}$ & $\begin{array}{r}\text { M2 (FE) } \\
\text { (4) }\end{array}$ & $\begin{array}{r}\text { M2 (RE) } \\
\text { (5) }\end{array}$ & $\begin{array}{r}\text { M2 (CSD) } \\
(6)\end{array}$ & $\begin{array}{r}\text { M3 (FE) } \\
\text { (7) }\end{array}$ & $\begin{array}{r}\text { M3 (RE) } \\
\text { (8) }\end{array}$ & $\begin{array}{r}\text { M3 (CSD) } \\
(9)\end{array}$ \\
\hline Trade & & & & & & & & & \\
\hline Austria & -0.279 & -0.245 & -0.279 & -0.233 & -0.137 & -0.233 & -1.395 & -1.034 & $-1.394 *$ \\
\hline Belgium & -0.492 & -0.456 & -0.492 & $-0.638^{*}$ & -0.597 & $-0.638 *$ & $-1.244 \% * *$ & $-1.187 * * *$ & $-1.244 * * *$ \\
\hline Bulgaria & $-1.408 * * *$ & $-1.423 * * *$ & $-1.401 * *$ & $-0.962^{* *}$ & $-1.002 * *$ & $-0.962 *$ & -0.380 & -0.402 & -0.380 \\
\hline Canada & -0.101 & -0.071 & -0.101 & 0.400 & 0.348 & 0.399 & 0.329 & 0.330 & 0.329 \\
\hline Croatia & $-0.508 * *$ & $-0.525^{* *}$ & $-0.508 *$ & -0.257 & -0.253 & -0.257 & -0.073 & -4.098 & -0.073 \\
\hline Cyprus & -0.187 & -0.177 & -0.187 & -0.099 & -0.054 & -0.100 & 0.125 & 0.219 & 0.125 \\
\hline Czechia & -0.267 & -0.283 & -0.267 & -0.263 & -0.269 & -0.263 & $-2.255^{* * * *}$ & $-1.979 * *$ & $-2.255^{* * *}$ \\
\hline Denmark & -0.447 & -0.406 & -0.447 & -0.555 & -0.456 & -0.555 & -0.185 & -0.027 & -0.185 \\
\hline Estonia & $-0.633^{* * *}$ & $-0.648 \% *$ & $-0.633^{* * *}$ & 0.134 & 0.222 & 0.134 & 0.193 & 0.268 & 0.193 \\
\hline Finland & -0.204 & -0.171 & -0.204 & 1.007 & $1.311 *$ & 1.008 & 0.706 & 0.974 & 0.707 \\
\hline France & -0.217 & -0.185 & -0.217 & -0.117 & -0.246 & -0.117 & $-0.698 * *$ & $-0.606^{*}$ & $-0.698 * *$ \\
\hline Germany & -0.194 & -0.161 & -0.194 & -0.270 & -0.201 & -0.270 & 0.668 & 0.781 & 0.668 \\
\hline Greece & -0.281 & -0.276 & -0.281 & -0.141 & -0.098 & -0.141 & 0.209 & 0.280 & 0.209 \\
\hline Hungary & $-0.505^{* *}$ & $-0.522 *$ & $-0.505^{*}$ & -0.337 & -0.350 & -0.337 & $-2.030 * *$ & $-1.768^{* *}$ & -2.030 \\
\hline Ireland & -0.371 & -0.335 & -0.371 & -0.119 & 0.005 & -0.119 & $-0.780 *$ & -0.670 & $-0.780^{*}$ \\
\hline Italy & -0.462 & -0.434 & -0.462 & -0.523 & -0.487 & -52.297 & 0.072 & 0.157 & 0.072 \\
\hline Latvia & $-0.803^{* * *}$ & $-0.819 * * *$ & $-0.803 * * *$ & -0.308 & -0.288 & -0.308 & -0.026 & 0.005 & -0.026 \\
\hline Lithuania & $-0.572 *$ & $-0.596^{*}$ & -0.572 & 0.020 & 0.008 & 0.020 & -0.056 & -0.007 & -0.056 \\
\hline Luxembourg & $-2.200 * *$ & $-2.172 * *$ & -2.200 & $-3.254 * * *$ & $-3.201 * * *$ & $-3.255^{* *}$ & $-4.661 * * *$ & $-4.502 * * *$ & $-4.661 * * *$ \\
\hline Malta & $-0.346 * * *$ & $-0.345 * * *$ & $-0.346 * * *$ & $-0.327^{* * *}$ & $-0.348 * * *$ & $-0.327 * *$ & $-0.832^{* * *}$ & $-0.838^{* * *}$ & $-0.832 * * *$ \\
\hline Nederlands & -0.237 & -0.201 & -0.237 & -0.361 & -0.294 & -0.361 & 0.709 & 0.823 & 0.709 \\
\hline Poland & $-0.897 * * *$ & $-0.909 \% * *$ & $-0.897 * * *$ & $-0.646 * *$ & $-0.680 \%$ & $-0.646^{*}$ & -0.098 & -0.095 & -0.098 \\
\hline Portugal & -0.222 & -0.222 & -0.222 & -0.114 & -0.088 & -0.114 & 0.540 & 0.590 & 0.540 \\
\hline Romania & $-1.080 * * *$ & $-1.100 * * *$ & $-1.080 * * *$ & $-0.784 * *$ & $-0.826 * *$ & $-0.784 *$ & -0.273 & -0.291 & -0.273 \\
\hline Slovakia & -0.171 & -0.172 & -0.171 & -0.009 & 0.024 & -0.009 & 0.321 & 0.394 & 0.321 \\
\hline Slovenia & -0.185 & -0.171 & -0.185 & 0.002 & 0.064 & 0.002 & 0.650 & 0.740 & 0.650 \\
\hline Spain & $-0.475 * *$ & $-0.493 * *$ & -0.475 & -0.317 & -0.330 & -0.317 & $-1.711 \% *$ & $-1.464^{*}$ & $-1.711 * *$ \\
\hline Sweden & -0.301 & -0.263 & -0.301 & 0.578 & 0.847 & 0.578 & -0.011 & 0.263 & -0.011 \\
\hline UK & -0.165 & -13.149 & -0.165 & -0.185 & -0.115 & -0.185 & $-1.122 * * *$ & $-1.011^{* * *}$ & $-1.122^{* * *}$ \\
\hline Average & $-0.490 * * *$ & $-0.480 * * *$ & $-0.490 * * *$ & -0.299 & -0.248 & -0.299 & $-0.459 *$ & -0.348 & $-0.459^{*}$ \\
\hline
\end{tabular}

Note: The entries in this table are elasticities. The average Trade to GDP ratio in the sample is around $0.057 \%$. Thus, in response to a $0.01 \%$ percentage point increase in Trade, CO2 per capita in Bulgaria should decrease by approximately $1.40 \%$ (i.e., exp $(0.0001 * \epsilon)-1 ; \epsilon$ is one of the elasticity coefficients in the table). Columns (1), (2), and (3) show coefficients of Trade elasticities using Model 1 (M1) under Fixed Effects (FE), Random Effects (RE), and Fixed Effects with Cross-Sectional Dependence Robust Standard Error Terms (CSD), respectively. Columns (4), (5), and (6) indicate Trade elasticities for CO2 using Model 2 (M2) under Fixed Effects (FE), Random Effects (RE), and Fixed Effects with Cross-Sectional Dependence Robust Standard Error Terms (CSD), respectively. Columns (7), (8), and (9) indicate Trade elasticities for CO2 Model 3 (M3) under Fixed Effects (FE), Random Effects (RE), and Fixed Effects with Cross-Sectional Dependence Robust Standard Error Terms (CSD), respectively. ***, $* *$, and * denote significance at the $1 \%, 5 \%$, and $10 \%$ significance level, respectively. The study employs the Delta method to compute the Trade elasticities. The last row reports the average Trade elasticities for CO2 across all CETA members. 
Table 9: Trade Elasticity of CH4 Coefficients

\begin{tabular}{|c|c|c|c|c|c|c|c|c|c|}
\hline Estimation Method & $\begin{array}{r}\text { M1 (FE) } \\
\text { (1) }\end{array}$ & $\begin{array}{r}\text { M1 (RE) } \\
(2)\end{array}$ & $\begin{array}{r}\text { M1 (CSD) } \\
\text { ( } 3 \text { ) }\end{array}$ & $\begin{array}{r}\text { M2 (FE) } \\
(4) \\
\end{array}$ & $\begin{array}{r}\text { M2 (RE) } \\
(5) \\
\end{array}$ & $\begin{array}{r}\text { M2 (CSD) } \\
(6) \\
\end{array}$ & $\begin{array}{r}\text { M3 (FE) } \\
(7)\end{array}$ & $\begin{array}{r}\text { M3 (RE) } \\
(8) \\
\end{array}$ & $\begin{array}{r}\text { M3 (CSD) } \\
(9) \\
\end{array}$ \\
\hline Trade & & & & & & & & & \\
\hline Austria & $-0.807 * * *$ & $-0.602 * *$ & $-0.807 * * *$ & $-1.296 * * *$ & $-1.159 * * *$ & $-1.296 * * *$ & -0.166 & -0.177 & -0.166 \\
\hline Belgium & $-1.829 * * *$ & $-1.616^{* * * *}$ & $-1.829 * * *$ & $-2.097 * * *$ & $-1.971 \% * *$ & $-2.097 * * *$ & $-2.457 * * *$ & $-2.297 * * *$ & $-2.457 * * *$ \\
\hline Bulgaria & -0.281 & -0.439 & -0.281 & 0.606 & 0.448 & 0.606 & $0.931^{* *}$ & $0.796 *$ & 0.931 \\
\hline Canada & -0.226 & -0.061 & -0.227 & $1.192 * * *$ & $0.890 * *$ & $1.192 * * *$ & $1.232 * * *$ & $0.952 \% *$ & $1.232^{* * * *}$ \\
\hline Croatia & -0.319 & $-0.365^{*}$ & -0.319 & -0.316 & -0.257 & -0.316 & -0.245 & -0.132 & -0.245 \\
\hline Cyprus & $-1.261 * * *$ & $-1.142 * * *$ & $-1.261 * * *$ & $-1.694 * * *$ & $-1.533^{* * * *}$ & $-1.694 * * *$ & $-1.583 * * *$ & $-1.333 * * *$ & $-1.583 * *$ \\
\hline Czechia & $-1.234 * * *$ & $-1.201 * * *$ & $-1.234 * * *$ & $-1.548 * * *$ & $-1.382 * * *$ & $-1.548 * * *$ & -0.778 & -0.783 & -0.778 \\
\hline Denmark & -0.381 & -0.151 & -0.381 & $-0.790 * *$ & $-0.679 *$ & $-0.790 * *$ & -0.675 & -0.438 & -0.675 \\
\hline Estonia & -0.141 & -0.207 & -0.141 & -0.303 & -0.265 & -0.303 & -0.267 & -0.244 & -0.267 \\
\hline Finland & $-0.622 * *$ & $-0.430 *$ & $-0.622 * *$ & $-1.849 * * *$ & $-1.668 * *$ & $-1.849 * * *$ & $-1.961 * * *$ & $-1.831 * *$ & $-1.961 * * *$ \\
\hline France & $-0.517^{* * *}$ & -0.338 & $-0.517^{* * *}$ & $-0.963 * * *$ & $-0.841 \% * *$ & $-0.963 * * *$ & $-1.278 * * *$ & $-1.155^{* * * *}$ & $-1.278 * * *$ \\
\hline Germany & -0.357 & -0.172 & -0.357 & $-0.731 * * *$ & $-0.611 * *$ & $-0.731 * *$ & -0.308 & -0.071 & -0.308 \\
\hline Greece & $-1.706 * * *$ & $-1.597 * * *$ & $-1.706 * * *$ & $-2.165^{* * *}$ & $-1.992 \% * *$ & $-2.165^{* * *}$ & $-2.040 * \cdots *$ & $-1.788 * * *$ & $-2.040 * * *$ \\
\hline Hungary & -0.240 & -0.288 & -0.240 & -0.161 & -0.112 & -0.161 & 0.808 & 0.661 & 0.808* \\
\hline Ireland & $-0.559 * *$ & -0.375 & $-0.559 * *$ & $-1.032 * * *$ & $-0.925^{* * *}$ & $-1.032 \% * *$ & $-1.394 \% * *$ & $-1.306^{* * * *}$ & $-1.394 * * *$ \\
\hline Italy & $-2.150 * * *$ & $-1.961 * * *$ & $-2.150 * * *$ & $-2.461 * * *$ & $-2.317^{* * * *}$ & $-2.461 * * *$ & $-2.201 * * *$ & $-1.943 * * *$ & $-2.201 \% * *$ \\
\hline Latvia & -0.101 & -0.193 & -0.101 & 0.116 & 0.099 & 0.116 & 0.266 & 0.268 & 0.266 \\
\hline Lithuania & $-0.055^{*}$ & $-0.610^{* * *}$ & $-0.553 *$ & $-0.811^{* * *}$ & $-0.721 \% *$ & $-0.811^{* * * *}$ & $-0.908 * * *$ & $-0.812^{* * *}$ & $-0.908 * * *$ \\
\hline Luxembourg & $-2.112 * *$ & $-1.777^{*}$ & $-2.112 * * *$ & $-2.200 * *$ & $-2.089 * *$ & $-2.200 * * *$ & $-2.021 *$ & $-2.037^{*}$ & $-2.021 * *$ \\
\hline Malta & $0.169 * *$ & $0.164 *$ & 0.169 & $0.346^{* * * *}$ & $0.368 * * *$ & $0.346 * *$ & 0.117 & 0.138 & 0.117 \\
\hline Netherlands & -0.126 & 0.064 & -0.126 & -0.423 & -0.326 & -0.423 & 0.063 & 0.286 & 0.063 \\
\hline Poland & 0.007 & -0.092 & 0.007 & $0.557^{* * *}$ & $0.486^{* *}$ & $0.557^{*}$ & $0.868^{* *}$ & $0.850 \% *$ & $0.868^{* * *}$ \\
\hline Portugal & $-0.919 * * *$ & $-0.854 * * *$ & $-0.919 * * *$ & $-1.230 * * *$ & $-1.093^{* * *}$ & $-1.230 * * *$ & $-0.952^{* *}$ & $-0.735^{*}$ & -0.952 \\
\hline Romania & -0.249 & -0.377 & -0.249 & 0.357 & 0.280 & 0.357 & $0.603^{*}$ & 0.568 & 0.603 \\
\hline Slovakia & $-0.500 * *$ & $-0.451 * *$ & $-0.500 *$ & $-0.807 * * *$ & $-0.683 * * *$ & $-0.807 * * *$ & -0.642 & -0.443 & -0.642 \\
\hline Slovenia & $-0.902 * * *$ & $-0.790 * * *$ & $-0.902 * * *$ & $-1.321 * * *$ & $-1.182^{* * * *}$ & $-1.321 * * *$ & $-1.010 * *$ & $-0.796^{*}$ & $-1.010^{*}$ \\
\hline Spain & -0.176 & -0.226 & -0.176 & -0.119 & -0.065 & -0.119 & 0.962 & 0.820 & $0.962 * *$ \\
\hline Sweden & -0.386 & -0.171 & -0.386 & $-1.450 * *$ & $-1.286^{* * *}$ & $-1.450 * * *$ & $-1.706 * * *$ & $-1.547^{* * *}$ & $-1.706 * * *$ \\
\hline UK & 0.222 & 0.382 & 0.222 & -0.045 & 0.035 & -0.045 & -0.046 & -0.358 & -0.460 \\
\hline Average & $-0.635^{* * *}$ & $-0.552^{* * * *}$ & $-0.635^{* * * *}$ & $-0.794 * * * *$ & $-0.722^{* * * *}$ & $-0.794 * * *$ & $-0.614 * * *$ & $-0.534 \% *$ & $-0.614 * * *$ \\
\hline
\end{tabular}

Note: The entries in this table are elasticities. The average Trade to GDP ratio in the sample is around $0.057 \%$. Thus, in response to a $0.01 \%$ percentage point increase in Trade, CH4 per capita in Austria should decrease by approximately $0.81 \%$ (i.e., $\exp (0.0001 * \epsilon)-1 ; \epsilon$ is one of the elasticity coefficients in the table). Columns (1), (2), and (3) show coefficients of Trade elasticities for CH4 using Model 1 (M1) under Fixed Effects (FE), Random Effects (RE), and Fixed Effects with Cross-Sectional Dependence Robust Standard Error Terms (CSD), respectively. Columns (4), (5), and (6) indicate Trade elasticities for CH4 using Model 2 (M2) under Fixed Effects (FE), Random Effects (RE), and Fixed Effects with Cross-Sectional Dependence Robust Standard Error Terms (CSD), respectively. Columns (7), (8), and (9) indicate Trade elasticities for CH4 using Model 3 (M3) under Fixed Effects (FE), Random Effects (RE), and Fixed Effects with Cross-Sectional Dependence Robust Standard Error Terms (CSD), respectively. ***, **, and * denote significance at the $1 \%, 5 \%$, and $10 \%$ significance level, respectively. The study employs the Delta method to compute the Trade elasticities of $\mathrm{CH} 4$. The last row reports the average Trade elasticity for $\mathrm{CH} 4$ across all CETA members. 
Table 10: Trade Elasticity of N2O Coefficients

\begin{tabular}{|c|c|c|c|c|c|c|c|c|c|}
\hline Estimation Method & $\begin{array}{r}\text { M1 (FE) } \\
(1) \\
\end{array}$ & $\begin{array}{r}\text { M1 (RE) } \\
(2)\end{array}$ & $\begin{array}{r}\text { M1 (CSD) } \\
\text { ( } 3 \text { ) }\end{array}$ & $\begin{array}{r}\text { M2 (FE) } \\
(4) \\
\end{array}$ & $\begin{array}{r}\text { M2 (RE) } \\
(5) \\
\end{array}$ & $\begin{array}{r}\text { M2 (CSD) } \\
(6)\end{array}$ & $\begin{array}{r}\text { M3 (FE) } \\
(7) \\
\end{array}$ & $\begin{array}{r}\text { M3 (RE) } \\
(8) \\
\end{array}$ & $\begin{array}{r}\text { M3 (CSD) } \\
(9) \\
\end{array}$ \\
\hline Trade & & & & & & & & & \\
\hline Austria & $-2.307 * * *$ & $-2.216 * * * *$ & $-2.307 * * *$ & $-2.346 * * *$ & $-2.245^{* * *}$ & $-2.346 * * *$ & $-3.848 * * *$ & $-3.505 * * *$ & $-3.848 * * *$ \\
\hline Belgium & $-3.207 * * * *$ & $-3.111^{* * * *}$ & $-3.207 * * *$ & $-3.555 * * *$ & $-3.502 * * *$ & $-3.555 \% * *$ & $-3.467 * \cdots *$ & $-3.381^{* * * *}$ & $-3.467 * * *$ \\
\hline Bulgaria & 0.279 & 0.210 & 0.279 & $0.971 *$ & 0.939* & 0.971 & 0.563 & 0.533 & 0.563 \\
\hline Canada & $-1.585^{* * * *}$ & $-1.508 * * *$ & $-1.585^{* * *}$ & -0.529 & -0.495 & $-0.529 *$ & -0.579 & -0.565 & $-0.579 * *$ \\
\hline Croatia & 0.002 & -0.033 & 0.002 & $0.509 *$ & $0.501 *$ & $0.509^{*}$ & -0.011 & 0.037 & -0.011 \\
\hline Cyprus & $-1.878 * * *$ & $-1.832 * * *$ & $-1.878 * * *$ & $-1.711 * * *$ & $-1.671 * * *$ & $-1.711 * * *$ & $-2.559 * * *$ & $-2.424 * * *$ & $-2.559 * * *$ \\
\hline Czechia & $-1.023 *$ & $-1.033^{*}$ & $-1.023 * *$ & -0.862 & $-0.884 *$ & $-0.862 * *$ & $-2.070 *$ & $-1.821 *$ & $-2.070 * *$ \\
\hline Denmark & $-2.180 * * *$ & $-2.083 * * *$ & $-2.180 * * *$ & $-2.516^{* * * *}$ & $-2.409 * * *$ & $-2.516^{* * *}$ & $-3.513 * * *$ & $-3.309 * * *$ & $-3.513 * * *$ \\
\hline Eston & 0.163 & 0.123 & 0.163 & $1.442^{* * *}$ & $1.521 * * *$ & $1.442^{* *}$ & $1.504 * * *$ & $1.573 * * *$ & $1.504^{* * *}$ \\
\hline Finland & $-2.070 * * *$ & $-1.983 * * *$ & $-2.070 * * *$ & -0.283 & 0.024 & -0.283 & 0.180 & 0.452 & 0.180 \\
\hline Franc & $-1.921 * * *$ & $-1.838 * * *$ & $-1.921 * * *$ & $-1.860 * * *$ & $-1.764 * * *$ & $-1.860 \% * *$ & $-1.600 * * *$ & $-1.494 * * *$ & $-1.600 * * *$ \\
\hline Germa & $-1.816 * * *$ & $-1.733 * * *$ & $-1.816^{* * * *}$ & $-2.029 * * *$ & $-1.957 * * *$ & $-2.029 * * *$ & $-3.238 * * *$ & $-3.080 * * *$ & $-3.238 * * *$ \\
\hline Greece & $-2.108 * * *$ & $-2.071 * * *$ & $-2.108 * * *$ & $-1.840 * * *$ & $-1.801 \% * *$ & $-1.840 * * *$ & $-2.549 * * *$ & $-2.440 * * *$ & $-2.549 * * *$ \\
\hline Hungary & 0.068 & 0.032 & 0.068 & $0.445 *$ & 0.421 & $0.445^{*}$ & -0.735 & -0.519 & -0.735 \\
\hline Ireland & $-2.059 * *$ & $-1.974 * * *$ & $-2.059 * * *$ & $-1.800 * * *$ & $-1.668^{* * *}$ & $-1.800 * * *$ & $-1.314^{* *}$ & $-1.197^{* * *}$ & $-1.314 * * *$ \\
\hline Italy & $-3.226 * * *$ & $-3.142 * * *$ & $-3.226 * * *$ & $-3.396 * * *$ & $-3.350 * * *$ & $-3.396 * * *$ & $-4.447 * * *$ & $-4.311^{* * * *}$ & $-4.447 * * *$ \\
\hline Latvia & 0.290 & 0.240 & 0.290 & $1.132 * * *$ & $1.147^{* * * *}$ & $1.132 * *$ & $0.840 * *$ & $0.871 * *$ & 0.840 \\
\hline Lithuania & -0.071 & -0.055 & -0.007 & $1.059 * *$ & $1.107 * *$ & $1.059^{*}$ & $1.101^{* *}$ & $1.156^{* * *}$ & $1.101^{* * *}$ \\
\hline Luxembourg & $-3.804 * * *$ & $-3.740 * * *$ & $-3.804 * * *$ & $-5.725 * * *$ & $-5.662 * * *$ & $-5.725^{* * *}$ & $-5.525 * * *$ & $-5.413^{* * * *}$ & $-5.525^{* * *}$ \\
\hline Malta & -0.099 & -0.100 & -0.099 & -0.027 & -0.054 & -0.027 & 0.092 & 0.088 & 0.092 \\
\hline Netherlands & $-1.742 * * *$ & $-1.654 * * *$ & $-1.742 * * *$ & $-2.052 * * *$ & $-1.987^{* * * *}$ & $-2.059 * * *$ & $-3.361 * * *$ & $-3.202 * * *$ & $-3.361 * * *$ \\
\hline Poland & 0.292 & 0.247 & 0.292 & $0.722^{* *}$ & $0.687^{* *}$ & 0.722 & 0.019 & 0.030 & 0.019 \\
\hline Portugal & $-1.210 * * *$ & $-1.191 * * *$ & $-1.210 * * *$ & $-0.970 * * *$ & $-0.953 * * *$ & $-0.970 * * *$ & $-1.815^{* * * *}$ & $-1.732^{* * *}$ & $-1.815^{* * * *}$ \\
\hline Romania & 0.337 & 0.271 & 0.337 & $0.859 * *$ & $0.817 * *$ & 0.859 & 0.355 & 0.336 & 0.355 \\
\hline Slovakia & $-0.782 * * *$ & $-0.769 * * *$ & $-0.782 * * *$ & -0.454 & -0.431 & $-0.454^{*}$ & $-1.239 * *$ & $-1.135^{* * *}$ & $-1.239 * *$ \\
\hline Slovenia & $-1.634 * \cdots *$ & $-1.586 * * *$ & $-1.634 * * *$ & $-1.337 * * *$ & $-1.277^{* * * *}$ & $-1.337 * * *$ & $-2.191 * \cdots *$ & $-2.066^{* * *}$ & $-2.191 * * *$ \\
\hline Spain & & & 0.150 & $0.520 *$ & & $0.520 *$ & -0.694 & -0.495 & -0.694 \\
\hline Sweden & $2.064 * * *$ & $-1.970 * * *$ & $-2.064 * * *$ & -0.836 & -0.5 & -0.836 & -0.647 & -0.357 & -0.647 \\
\hline UK & $-1.278 * * *$ & $-1.200 * * *$ & $-1.278 * * *$ & $-1.414 * * *$ & $-1.342 * * *$ & $-1.414 * * *$ & $-1.347 * * *$ & $-1.217^{* * *}$ & $-1.347 * * *$ \\
\hline Average & $-1.256^{* * * *}$ & $-1.227^{* * *}$ & $-1.256^{* * * *}$ & $-0.961 * * *$ & $-0.909 \div * *$ & $-0.961 * * *$ & $-1.451^{* * * *}$ & $-1.330 * * *$ & $-1.451 * * *$ \\
\hline
\end{tabular}

Note: The entries in this table are elasticities. The average Trade to GDP ratio in the sample is around $0.057 \%$. Thus, in response to a $0.01 \%$ percentage point increase in Trade, N2O per capita in Austria should decrease by approximately $2.307 \%$ (i.e., $\exp (0.0001 * \epsilon)-1 ; \epsilon$ is one of the elasticity coefficients in the table). Columns (1), (2), and (3) show coefficients of Trade elasticities for N2O using Model 1 (M1) under Fixed Effects (FE), Random Effects (RE), and Fixed Effects with Cross-Sectional Dependence Robust Standard Error Terms (CSD), respectively. Columns (4), (5), and (6) indicate Trade elasticities for N2O using Model 2 (M2) under Fixed Effects (FE), Random Effects (RE), and Fixed Effects with Cross-Sectional Dependence Robust Standard Error Terms (CSD), respectively. Columns (7), (8), and (9) indicate Trade elasticities for N2O using Model 3 (M3) under Fixed Effects (FE), Random Effects (RE), and Fixed Effects with Cross-Sectional Dependence Robust Standard Error Terms (CSD), respectively. ***, **, and * denote significance at the $1 \%, 5 \%$, and $10 \%$ significance level, respectively. The study employs the Delta method to compute the Trade elasticities of N2O. The last row reports the average Trade elasticity of N2O across all CETA Members. 


\section{Table 11: Trade Elasticity of HFC/PFC/SF6 (F-Gasses) Coefficients}

\begin{tabular}{|c|c|c|c|c|c|c|c|c|c|}
\hline Estimation Method & $\begin{array}{r}\text { M1 (FE) } \\
\text { (1) }\end{array}$ & $\begin{array}{r}\text { M1 (RE) } \\
\text { ( } 2 \text { ) }\end{array}$ & $\begin{array}{r}\text { M1 (CSD) } \\
\text { ( } 3 \text { ) }\end{array}$ & $\begin{array}{r}\text { M2 (FE) } \\
\text { (4) }\end{array}$ & $\begin{array}{r}\text { M2 (RE) } \\
\text { (5) }\end{array}$ & $\begin{array}{r}\text { M2 (CSD) } \\
(6)\end{array}$ & $\begin{array}{r}\text { M3 (FE) } \\
\text { (7) }\end{array}$ & $\begin{array}{r}\text { M3 (RE) } \\
\text { (8) }\end{array}$ & $\begin{array}{r}\text { M3 (CSD) } \\
(9)\end{array}$ \\
\hline Trade & & & & & & & & & \\
\hline Austria & -2.376 & -0.585 & $-2.376^{*}$ & 0.713 & 0.020 & 0.713 & 0.410 & $-3.505^{* * *}$ & 0.410 \\
\hline Belgium & $-4.582 * *$ & $-2.749 *$ & $-4.582 * * *$ & -2.945 & -3.128 & $-2.945^{*}$ & -3.722 & $-3.381 * * *$ & $-3.722^{* *}$ \\
\hline Bulgaria & $5.351 * *$ & 2.134 & $5.351^{* *}$ & $5.888 * *$ & 3.375 & $5.888 * *$ & 4.331 & 0.533 & $4.331 *$ \\
\hline Canada & -1.495 & 0.460 & -1.495 & -2.398 & 0.351 & $-2.398^{* *}$ & -2.353 & -0.565 & $-2.353^{* *}$ \\
\hline Croatia & $2.446^{*}$ & 1.275 & $2.446^{*}$ & $2.525^{*}$ & 1.797 & $2.525^{*}$ & -0.520 & 0.037 & -0.520 \\
\hline Cyprus & $-3.228 *$ & -1.758 & $-3.228 *$ & -2.023 & -1.651 & -2.02 & $-6.658 * *$ & $-2.424 * * *$ & $-6.658 * *$ \\
\hline Czechia & -0.620 & -0.830 & -0.620 & -1.540 & -1.312 & -1.540 & -1.315 & $-1.821 *$ & -1.315 \\
\hline Denmark & -0.258 & 0.743 & -0.258 & 2.883 & 1.145 & $2.883 *$ & -2.736 & $-3.309 * * *$ & -2.736 \\
\hline Estonia & $3.391 * * *$ & $1.780 *$ & $3.391 * * *$ & $6.615^{* * *}$ & $4.357 * *$ & $6.615 * * *$ & $7.048 * * *$ & $1.573 * * *$ & $7.048 * * *$ \\
\hline Finland & -2.183 & -0.283 & $-2.183^{*}$ & 8.010* & 4.849 & $8.010 * * *$ & $10.770 * *$ & 0.452 & $10.770 * * *$ \\
\hline France & -1.873 & -5.877 & -1.873 & 1.134 & 0.682 & 1.134 & 1.666 & $-1.494 * * *$ & 1.666 \\
\hline Germany & -1.386 & 0.349 & -1.386 & 0.688 & 0.471 & 0.688 & -5.076 & $-3.080 * * *$ & -5.076 \\
\hline Greece & -3.423 & -2.316 & -3.423 & -2.238 & -2.103 & -2.238 & $-6.115^{*}$ & $-2.440 * * *$ & $-6.115 * *$ \\
\hline Hungary & $2.822 * *$ & 1.507 & $2.822^{* *}$ & $2.311^{*}$ & 1.711 & $2.311^{*}$ & 3.416 & -0.519 & $3.412^{*}$ \\
\hline Ireland & -1.479 & .325 & -1.479 & 2.807 & 1.443 & $2.807^{*}$ & $4.506^{*}$ & $-1.197 * *$ & $4.506^{* * *}$ \\
\hline Italy & $-5.310 * *$ & $-3.469 *$ & $-5.310 * * *$ & -3.866 & $-3.761 *$ & $-3.866^{* *}$ & $-9.281 * *$ & $-4.311 * * *$ & $-9.281 * * *$ \\
\hline Latvia & $3.700 * * *$ & $1.973 * *$ & $3.700 * * *$ & $5.207 * * *$ & $3.532^{* *}$ & $5.207 * * *$ & $3.849 * *$ & $0.871^{* *}$ & $3.849^{* *}$ \\
\hline Lithuania & 2.348 & 0.832 & 2.348 & $4.457^{*}$ & 2.672 & $4.457^{* * *}$ & $4.206^{*}$ & $1.156^{* *}$ & $4.206 * *$ \\
\hline Luxembourg & 7.467 & 1.055 & $7.467^{* * *}$ & 8.147 & -0.971 & $8.147^{* *}$ & $12.460 *$ & $-5.413 * * *$ & $12.460 * * *$ \\
\hline Malta & $1.525 * * *$ & $1.674 * * *$ & $1.525 * *$ & 0.927 & $1.419 * *$ & 0.927 & 0.795 & 8.802 & 0.795 \\
\hline Netherlands & -0.787 & 0.862 & -0.787 & 1.319 & 0.933 & 1.319 & -4.792 & $-3.202^{* * *}$ & -4.792 \\
\hline Poland & $4.214^{* *}$ & 2.187 & $4.214 * * *$ & $4.004 * *$ & 2.736 & $4.004 * *$ & 0.734 & 0.030 & 0.734 \\
\hline Portugal & -1.268 & -0.580 & -1.268 & -0.743 & -0.469 & -0.743 & -4.923 & $-1.732^{* * *}$ & $-4.923 *$ \\
\hline Romania & $5.025 * *$ & 2.012 & $5.025 * * *$ & $4.565 * *$ & 2.618 & $4.565^{* *}$ & 2.115 & 0.336 & 2.115 \\
\hline Slovakia & -0.273 & 0.307 & -0.273 & 0.472 & 0.667 & 0.472 & -3.618 & $-1.135 * *$ & -3.618 \\
\hline Slovenia & -2.274 & -0.823 & -2.274 & -0.341 & -0.212 & -0.341 & -4.323 & $-2.066 * * *$ & $-4.323^{*}$ \\
\hline Spain & $2.992^{* *}$ & 1.656 & $2.992^{* * *}$ & $2.400 *$ & 1.830 & $2.400 *$ & 3.604 & -0.495 & $3.604 *$ \\
\hline Sweden & -1.034 & 0.463 & -1.034 & $7.858 * *$ & 4.575 & $7.858 * * *$ & $8.414^{* * *}$ & -0.357 & $8.414^{* * *}$ \\
\hline UK & -0.179 & 1.496 & -0.179 & 2.076 & 1.882 & 2.076 & 1.290 & $-1.217^{* *}$ & 1.290 \\
\hline Average & 0.133 & 0.271 & 0.133 & 1.95 & 0.95 & $1.95^{* * *}$ & 0.410 & 0.398 & 0.410 \\
\hline
\end{tabular}

Note: The entries in this table are elasticities. The average Trade to GDP ratio in the sample is around $0.057 \%$. Thus, in response to a $0.01 \%$ percentage point increase in Trade, HFC/PFC/SF6 per capita in Cyprus should decrease by approximately 3.228\% (i.e., $\exp (0.0001 * \epsilon)-1 ; \epsilon$ is one of the elasticity coefficients in the table). Columns (1), (2), and (3) show coefficients of Trade elasticities for HFC/PFC/SF6 using Model 1 (M1) under Fixed Effects (FE), Random Effects (RE), and Fixed Effects with Cross-Sectional Dependence Robust Standard Error Terms (CSD), respectively. Columns (4), (5), and (6) indicate Trade elasticities for HFC/PFC/SF6 using Model 2 (M2) under Fixed Effects (FE), Random Effects (RE), and Fixed Effects with Cross-Sectional Dependence Robust Standard Error Terms (CSD), respectively. Columns (7), (8), and (9) indicate Trade elasticities for HFC/PFC/SF6 using Model 3 (M3) under Fixed Effects (FE), Random Effects (RE), and Fixed Effects with Cross-Sectional Dependence Robust Standard Error Terms (CSD), respectively. ***, **, and * denote significance at the 1\%, 5\%, and 10\% significance level, respectively. The study employs the Delta method to compute the Trade elasticities of HFC/PFC/SF6. The last row reports the average Trade elasticity for HFC/PFC/SF6 across all CETA members. 